Document downloaded from:

http://hdl.handle.net/10251/33998

This paper must be cited as:

Lobera González, MP.; Balaguer Ramirez, M.; García Fayos, J.; Serra Alfaro, JM. (2012).

Rare Earth-doped Ceria Catalysts for ODHE Reaction in a Catalytic Modified MIEC Membrane Reactor. ChemCatChem. 4(12):2102-2111. doi:10.1002/cctc.201200212

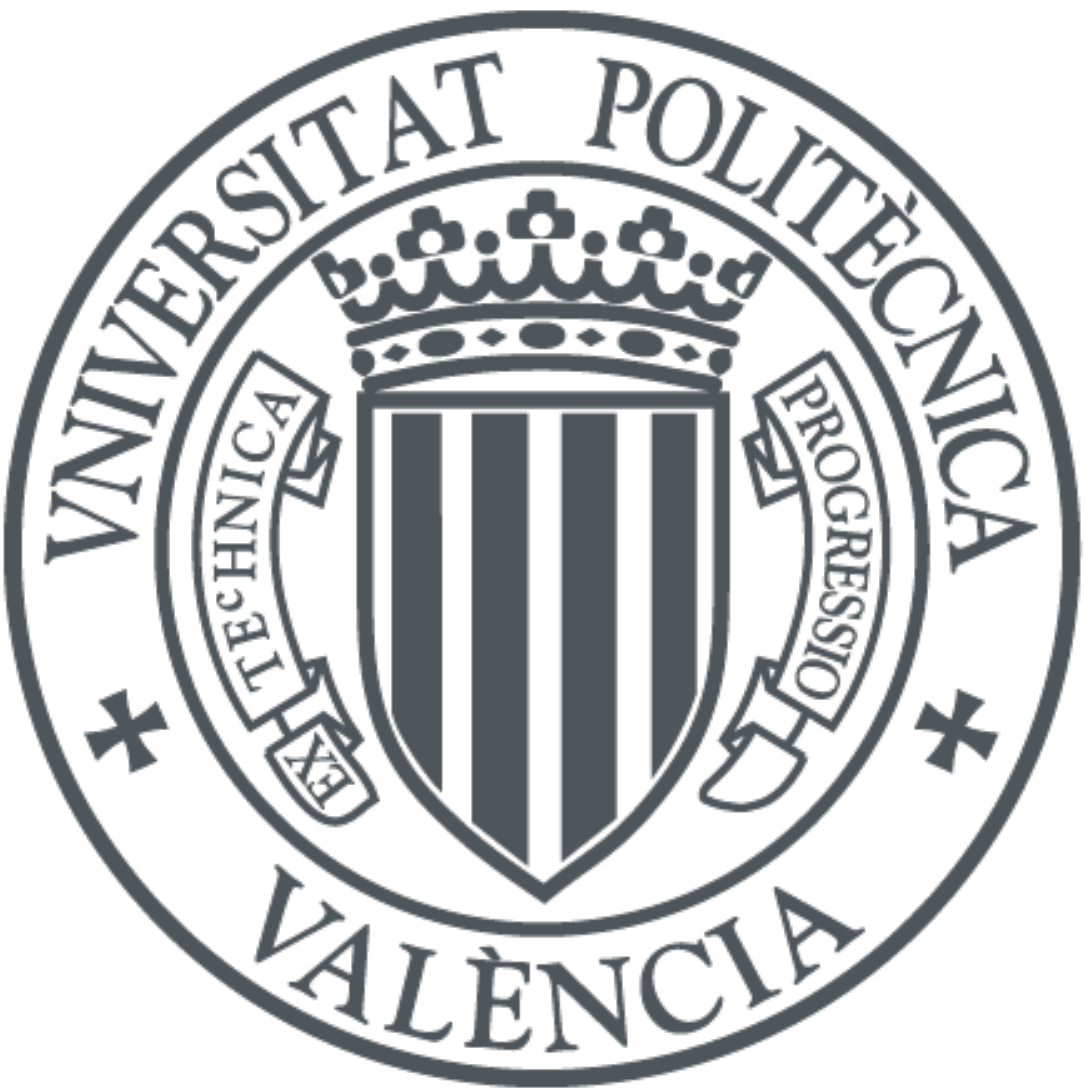

The final publication is available at

http://dx.doi.org/10.1002/cctc.201200212

Copyright Wiley-VCH Verlag

Additional Information 


\title{
Rare Earth-doped Ceria Catalysts for ODHE Reaction in a Catalytic Modified MIEC Membrane Reactor
}

\author{
M. Pilar Lobera, María Balaguer, Julio Garcia-Fayos, José M. Serra* \\ Instituto de Tecnología Química (Universidad Politécnica de Valencia - Consejo Superior de \\ Investigaciones Científicas), Av. Naranjos s/n, E-46022 Valencia, Spain \\ Published in ChemCatChem. (doi: 10.1002/cctc.201200212)
}

\begin{abstract}
An intensification process for the selective oxidation of hydrocarbons integrates a catalytic reactor and oxygen separation membrane. This work presents the study of oxidative dehydrogenation of ethane at $850^{\circ} \mathrm{C}$ in a catalytic membrane reactor based on mixed ionic-electronic conducting (MIEC) membranes. The surface of the membrane made of $\mathrm{Ba}_{0.5} \mathrm{Sr}_{0.5} \mathrm{Co}_{0.8} \mathrm{Fe}_{0.2} \mathrm{O}_{3-\delta}$ has been activated using different porous catalytic layers based on rare earth-doped cerias (fluorite structure) while the porous catalytic coating was deposited by screen printing (coating around $15 \mu \mathrm{m}$ ). The different catalyst formulations were developed by partial substitution of cerium and were synthesized by co-precipitation followed by cobalt impregnation when required. Specifically, seven different catalyst based on the system $\mathrm{Ce}_{1-\mathrm{x}} \mathrm{Ln}_{\mathrm{x}} \mathrm{O}_{2-\delta}$ ( $\mathrm{x}=0.1$ or $0.2 ; \mathrm{Ln}=\mathrm{Tb}, \mathrm{Pr}, \mathrm{Er}, \mathrm{Gd}$ and $\mathrm{Tb}+\mathrm{Er}$ ) including the effect of cobalt addition (2\% molar) in $\mathrm{Ce}_{0.8} \mathrm{~Tb}_{0.2} \mathrm{O}_{2-\delta}$ were studied. The ceria catalysts were studied by XRD, SEM, DC-conductivity as a function of oxygen partial pressure while the high-temperature stability in $\mathrm{CO}_{2}$ environment was assessed using thermogravimetry. Then, the influence of the ceria catalytic coating on the oxygen permeation flux through the MIEC membrane was studied when using argon and methane as sweep gas in the permeate side. Finally, the ODHE reaction tests were carried out at $850^{\circ} \mathrm{C}$ as a function of the ethane concentration in the feed. The use of disk-shaped membrane in the reactor made it possible to prevent the direct contact of gaseous oxygen and hydrocarbons and thus to increase the ethylene. High ethylene yields (up to $\sim 84 \%$ ) were obtained using a catalytic coating based on $20 \% \mathrm{~Tb}$ doped ceria including macropores produced by the addition of graphite platelets in the screen printing ink. The high yields obtained in this kind of catalytic membranes are attributed to the combination of: the high catalytic activity; the control of the oxygen concentration in the gas phase (reaction chamber); and the appropriate fluid dynamics, enabling the fast ethylene evacuation.
\end{abstract}

Keywords: Ethylene; catalyst, membrane reactor; BSCF membrane; ceria; ODHE

*Corresponding author.Tel:+34.963879448E-mail: jmserra@itq.upv.es 


\section{Introduction}

Ethylene is widely applied in important technical processes for production of other valuable base chemicals. It is mainly produced by steam cracking of alkanes from crude oil or natural gas, although it is a highly endothermic process with extensive coke formation, and the product mixture is rather complex and much effort is required for downstream processing ${ }^{[1]}$. Oxidative dehydrogenation of ethane $(O D H E)$ is one promising method to overcome the drawbacks of conventional method of ethylene production ${ }^{[1-2]}$.

Besides selecting an appropriate catalyst, advanced reactor concepts such as membrane reactor technology $(M R)$ appear promising to enhance performance in ODHE. A potential alternative is the use of a membrane reactor based on oxygen permeable mixed ion-electron conducting (MIEC) perovskite-based ceramics such as lanthanide ferrite cobaltites ${ }^{[3]}$. The process intensification achieved by the integration of gas separation membranes and high temperature reactors offers several advantages with respect to conventional process schemes, i.e. energy saving, safe operation, reduced plant/unit size and higher process performance. The membrane materials showing the highest oxygen permeability are based on $\mathrm{Ba}_{0.5} \mathrm{Sr}_{0.5} \mathrm{Co}_{0.8} \mathrm{Fe}_{0.2} \mathrm{O}_{3-\delta}$ (BSCF) which was first investigated by Shao et al. ${ }^{[4]}$ as ceramic membrane for oxygen separation from air. High oxygen permeation fluxes have been reported even in oxidizing conditions, for BSCF single phase materials ${ }^{[5]}$. Some MIEC membrane materials also possess catalytic activity for partial oxidation reactions. So besides the use as oxygen separation membrane, MIEC membranes also favor application as catalytic membrane reactor in selective oxidation of hydrocarbons. Figure 1 shows the principle of a MIEC dense membrane reactor: (1) on the oxygen rich compartment, gaseous $\mathrm{O}_{2}$ is first reduced to $\mathrm{O}^{2-}$, which (2) diffuses towards the reaction side through the crystal lattice via oxygen vacancy defect sites. And then (3) ethane is oxidized by surface $\mathrm{O}^{2-}$ and the surface oxygen is depleted in the reaction side ${ }^{[2 \mathrm{~g}]}$.

Moreover, it would be possible to increase its ethylene yield by using a proper porous catalytic layer on the membrane surface. Our previous study focused on the use catalytic coatings based on different perovskites, which have shown higher selectivity towards ethylene than the un-coated membrane ${ }^{[6]}$. However, catalysts must exhibit high chemical stability under both at higher temperatures and $\mathrm{CO}_{2}$-rich environments. Lanthanide doped-ceria materials $\left(\mathrm{Ce}_{1-x} \mathrm{Ln}_{x} \mathrm{O}_{2-\delta}\right)$ present an interesting combination of high oxygen-ion mobility, redox catalytic properties and stability in reducing, wet and $\mathrm{CO}_{2}$-rich atmospheres at high temperatures ${ }^{[7]}$. These features make these materials especially attractive for the use as catalyst for alkane activation reactions, as for ODHE. The redox catalytic properties of $\mathrm{Ce}_{1-\mathrm{x}} \mathrm{Ln}_{\mathrm{x}} \mathrm{O}_{2-\delta}$ suggest that these catalysts could operate according to the redox process proposed by Mars-van Krevelen ${ }^{[8]}$. Oxidation reactions in gas-phase with heterogeneous catalyst usually proceed via this mechanism, which involves the activation of the $\mathrm{C}-\mathrm{H}$ bond and transfer of lattice oxygen from the oxide to yield the product and the reduced catalyst. The combination of efficient catalysts and 
selective oxygen-transport membrane reactors may allow achieving important energy savings in the oxygen supply and significant improvements in the reactor productivity and catalyst selectivity.

In the present work, different doped-ceria catalysts were used to study their catalytic performance in the ODHE reaction at $850^{\circ} \mathrm{C}$ and different ethane concentrations in the feed were considered. The effect of their catalytic behavior was studied when different lanthanides were incorporated in the lattice of ceria. The catalysts were applied as $\sim 15$ $\mu \mathrm{m}$-thick porous coatings onto disk-shaped monolithic membranes made of BSCF.

\section{Experimental procedure}

\subsection{Catalyst preparation}

Lanthanide doped ceria compounds were prepared by co-precipitation method in order to synthesize powders of nanometric size. This technique consists of the dissolution of commercial lanthanide nitrates mixture in distilled water at $323 \mathrm{~K}$. $\left(\mathrm{NH}_{4}\right)_{2} \mathrm{CO}_{3}$ solution in a 1:1.5 molar ratio was dropped to achieve the total precipitation of the mixed cations. The resulting precursor powder was dried at $373 \mathrm{~K}$ after filtration and rinsing. Cobalt incorporation (when required) was carried out over the dried precursor powder by incipient wetness impregnation of cobalt nitrate. Calculated $2 \%$ molar of Co was dissolved in distilled water (volume corresponding to the pore volume) and mixed with the powder. Finally, the powders were calcined during 5 hours in air atmosphere at $1073 \mathrm{~K}$ to decompose the residual nitrates and carbonates and to favor the formation of fluorite phase. Table 1 lists the composition of the seven ceria-based catalysts synthesized.

\subsection{Characterization}

The powders were characterized by X-ray diffraction $(X R D)$ in a PANalytical Cubix fast diffractometer, using $\mathrm{CuK} \alpha_{1,2}$ radiation $(\lambda=1.5406 \AA)$ and an $\mathrm{X}^{\prime}$ Celerator detector in Bragg-Brentano geometry. XRD patterns were recorded in the $2 \theta$ range from $0^{\circ}$ to $90^{\circ}$ and analyzed using X'Pert Highscore Plus software. The crystalline phase was identified and lattice parameter $(a)$ for the $(h k l)$ planes was calculated using the equation for a cubic system.

The introduction of a dopant cation whose radius and valence are different from the host cations, produces a strain in the fluorite lattice. This strain is an estimation of the stress existing in the materials due to the crystal imperfections, oxygen vacancies, and other defects. The strain is calculated from the XRD pattern using the following equation 


$$
\beta_{\text {strain }}=\frac{4 \Delta d \sin \theta}{d \cos \theta}
$$

Where $\theta$ is the diffraction angle, and $\Delta d$ is the difference of the $d$ spacing corresponding to a typical peak of the structure with respect to pure ceria lattice.

Temperature programmed desorption $(T P D)$ measurements were performed in order to observe the oxygen release with temperature. The powder material $(100 \mathrm{mg})$ sintered at $1473 \mathrm{~K}$ was placed in a quartz reactor and it was heated up in air up to it $1273 \mathrm{~K}$ and cooled down in the same atmosphere. Then the sample was heated up at $10 \mathrm{~K} / \mathrm{min}$ up to $1273 \mathrm{~K}$ in $\mathrm{N}_{2}$ and the oxygen release was monitored by following the $m / z=32$ and 16 amu with a mass spectrometer Omnistar (Balzers).

Rectangular probes $\left(4 \times 0.4 \times 0.2 \mathrm{~cm}^{3}\right)$ of the powders fired at $1073 \mathrm{~K}$ were uniaxially pressed at $125 \mathrm{MPa}$ and subsequently sintered for 5 hours at $1573 \mathrm{~K}$ in air. Electrical conductivity measurements were conducted by standard four-point DC technique on the sintered rectangular bars using silver wire and paste for contacting. The measurements were carried out in a temperature range from 673 to $1073 \mathrm{~K}$ by cooling down $(1 \mathrm{~K} / \mathrm{min})$ in constant different $\mathrm{O}_{2}$ contained atmospheres (Linde calibrated gas mixtures checked by an YSZ oxygen sensor). The constant current was supplied by a programmable current source (Keithley 2601) and the voltage drop through the sample was detected by a multimeter (Keithley 3706). The conductivity measurements are thermally activated and were analysed on the basis of Arrhenius behaviour $\sigma(T)=(A / T) \exp \left(-E_{d} / k T\right)$. The activation energy $\left(E_{a}\right)$ was extracted from the slope of the graphs. Once the highest temperature $(1073 \mathrm{~K})$ was reached, the samples were stabilized for two hours in order to warrantee the high-temperature reduction state corresponding to the specific oxygen partial pressure $\left(\mathrm{pO}_{2}\right)$.

\subsection{Membrane surface modification}

Catalytic porous layers were deposited by screen-printing method on the surface of the permeate side. The screen-printing inks were prepared by a classic technique described previously ${ }^{[9]}$. The ball-milled catalyst powders were mixed with a solution of $94 \mathrm{wt} . \%$ terpineol and $6 \mathrm{wt} . \%$ ethylene cellulose. Graphite (Aldrich) was added as a pore former in the screen-printing ink, and then the ink homogenization was conducted using a three-roll mill. Subsequently, the coated membranes were sintered in air for $2 \mathrm{~h}$ at 1323 $\mathrm{K}$. During this process the graphite is removed and a proper microstructure of the catalytic coating is generated, which promotes the gas transport through porous catalytic layer. The microstructure of the catalytic modified membrane reactors was analyzed by scanning electron microscopy (SEM-EDS) in a JEOL JSM6300 electron microscope. 


\subsection{Membrane reactor setup and ODHE tests}

Oxygen permeation studies and investigations of the ODHE reaction were carried out in a reactor fully described in ${ }^{[2 \mathrm{~d}]}$. Figure $\mathrm{S} 1$ shows a scheme of the catalytic modified BSCF membrane reactor used in this work. Quartz membrane reactor was placed inside an electrical furnace. Temperature was measured by a thermocouple attached to the membrane surface (reaction side), while a proportional-integral-derivative (PID) controller maintained temperature variations within $2 \mathrm{~K}$ of the set point. Flow of all gas streams were individually controlled (Brooks). A mixture of synthetic air- $\mathrm{N}_{2}$ was fed to the feed side. In oxygen permeation experiments, either argon or diluted methane was used as sweep gas whilst diluted ethane was used as sweep gas in the ODHE tests. Online gas chromatograph (micro-GC Varian CP-4900 equipped with Molsieve5A, Pora-Plot-Q glass capillary and CP-Sil modules) was used to determine the concentration of the reaction products in the permeate gas stream.

The measurements were carried out on $15 \mathrm{~mm}$ diameter disk planar membrane (approximately $0.8 \mathrm{~mm}$ thick BSCF sintered disk). Membranes were prepared by uniaxial pressing and final sintering at $1100{ }^{\circ} \mathrm{C}$ following the procedure described in reference ${ }^{[2 c]}$ while sealing was performed using gold gaskets. Membrane gas leak-free conditions were confirmed by continuously monitoring the nitrogen concentration in the product gas stream. An acceptable sealing was achieved when the ratio between the oxygen flow leak and the oxygen flux was lower than $1 \%$. The oxygen permeation flux through the membrane, $J\left(\mathrm{O}_{2}\right)\left(\mathrm{ml} \mathrm{min}^{-1} \mathrm{~cm}^{-2}\right)$, was calculated considering the oxygen content measured in the reaction side of the permeation assembly, the sweep gas flow rate and the area of the membrane surface exposed to the flowing gas. Data reported are achieved at steady state after at least one hour on stream for a given operating condition. Each GC analysis was repeated three times to minimize analytical error. Reproducibility with regard to ODHE reaction for different membrane reactors is below $0.7 \%$. Carbon balances were always better than $\pm 2.3 \%$. Ethane conversion $\left(X_{\mathrm{C} 2 \mathrm{H} 6}\right)$, selectivity toward main products $\left(S_{i}\right)$ and ethylene yield $\left(Y_{C_{2 H}}\right)$ were defined as follows:

$$
\begin{aligned}
& X_{C_{2} H_{6}}=\frac{\sum_{i} n_{i} F_{i}^{\text {out }}-2 F_{C_{2} H_{6}}^{\text {out }}}{\sum_{i} n_{i} F_{i}^{\text {out }}} \times 100 \\
& S_{i}=\frac{n_{i} F_{i}^{\text {out }}}{\sum_{i} n_{i} F_{i}^{\text {out }}-2 F_{C_{2} H_{6}}^{\text {out }}} x 100 \\
& Y_{C_{2} \boldsymbol{H}_{4}}=\frac{\boldsymbol{X}_{C_{2} \boldsymbol{H}_{6}} \boldsymbol{S}_{C_{2} \mathrm{H}_{4}}}{100}
\end{aligned}
$$

where $i$ includes all reaction products with carbon atoms in the permeate gas stream, $n_{i}$ is the number of carbon atoms of component $i$, and $F_{i}$ is its molar flow. 
Fixed-bed catalyst tests were conducted in a quartz glass reactor. The bed was supported on a quartz frit. One gram of catalyst with particle size in the range $0.2-0.5 \mathrm{~mm}$ was mixed with $1 \mathrm{ml}$ of CSi (Carlo Erba). The gas feed consisted of a mixture of $\mathrm{C}_{2} \mathrm{H}_{6} / \mathrm{O}_{2} / \mathrm{Ar}$ and a fixed gas flow rate of $400 \mathrm{ml} \mathrm{min}^{-1}$. The ethane concentration was kept constant $(7.5 \%)$ while the oxygen concentration was varied in the range from 0.26 to $2.44 \%$.

\section{Results and Discussion}

\subsection{Characterization}

XRD patterns of $\mathrm{Ce}_{1-\mathrm{x}} \mathrm{Ln}_{\mathrm{x}} \mathrm{O}_{2-\delta}$ sintered at $1573 \mathrm{~K}$ are shown in Figure 2a. All the powders are single cubic fluorite structured. Diffraction peaks corresponding to any precursor or secondary phase were not observed. The obtained patterns indicate that the lanthanides are incorporated in the lattice of ceria. $\mathrm{Ce}_{0.8} \mathrm{~Tb}_{0.2} \mathrm{O}_{2-\delta}+\mathrm{Co} 2 \%$ has a slightly shorter cell parameter than Co-free sample attributed to the partial (1.3 mol\%) incorporation of Co cations into the ceria lattice and higher oxidation state in the Co containing compounds is observed i.e., 38\% (Co-free) and 48\% (Co-containing) on $\mathrm{Tb}^{+4} / \mathrm{Tb}$ ratio ${ }^{[7 \mathrm{a}]}$. In addition, $\mathrm{Ce}_{0.8} \mathrm{~Tb}_{0.2} \mathrm{O}_{2-\delta}+\mathrm{Co} 2 \%$ shows sharper and more intense diffraction peaks than the other specimens, which indicate greater grain size. It is reported that cobalt is a sintering aid that lowers the densification temperature ${ }^{[10]}$ resulting in higher grain size growth when the same sintering temperature is used. SEM pictures of $\mathrm{Ce}_{0.8} \mathrm{~Tb}_{0.2} \mathrm{O}_{2-\delta}$ and $\mathrm{Ce}_{0.8} \mathrm{~Tb}_{0.2} \mathrm{O}_{2-\delta}+\mathrm{Co} 2 \%$ membranes calcined at $1473 \mathrm{~K}$ in Figure $2 \mathrm{~b}$ confirm the effect of cobalt addition in the sintering activity.

At relevant ODHE operating conditions, different redox processes dependent on temperature and $\mathrm{pO}_{2}$ take place albeit the fluorite structure remains stable. Specifically, when multivalent lanthanides $\left(\mathrm{Tb}^{+3 /+4}\right.$ or $\left.\mathrm{Pr}^{+3 /+4}\right)$ are present, the thermal reduction of these cations and the consequent oxygen vacancy formation lead to changes in the electronic and ionic conductions properties as well as structural changes due to the additional chemical expansion. Table 1 summarizes the cell parameters (cubic fluorite) extracted from XRD patterns and non-stoichiometry in air determine by thermogravimetry, both at room temperature and $1073 \mathrm{~K}$ (relevant operation temperature for the oxygen membrane).

Figure 3 presents the Arrhenius plot corresponding to the total DC conductivity in air of the different catalysts. The incorporation of trivalent lanthanides such as $\mathrm{Gd}$ or Er induces the formation of a fixed number of oxygen vacancies regardless of the specific $\mathrm{pO}_{2}$, while doping with lanthanides with mixed valence $(+3 /+4)$ such as $\mathrm{Tb}$ or $\mathrm{Pr}$ are able to release oxygen as the temperature rises, even under oxidizing conditions. Consequently redox activity in the temperature range where the conductivity is 
measured provokes a change in the Arrhenius slope (apparent activation energy, $\mathrm{E}_{\mathrm{a}}$ ) for $\mathrm{Tb}$ and $\mathrm{Pr}$ doped ceria in air. Table 1 summarizes the total conductivity and $\mathrm{E}_{\mathrm{a}}$ of the ceria-based catalysts. The best conductivity was found for $\mathrm{Ce}_{0.8} \operatorname{Tb}_{0.1} \mathrm{Er}_{0.1} \mathrm{O}_{2-\delta}$ although it decreased steeply with decreasing temperatures due to the high $E_{a} \cdot \mathrm{Ce}_{0.8} \mathrm{Gd}_{0.2} \mathrm{O}_{2-\delta}$ combines high conductivity and low $\mathrm{E}_{\mathrm{a}}$ and this compound has been widely studied as solid oxide fuel cell electrolyte ${ }^{[11]}$, ${ }^{[12]},{ }^{[13]}$. The addition of Co to $\mathrm{Ce}_{0.8} \mathrm{~Tb}_{0.2} \mathrm{O}_{2-\delta}$ results in the enhancement of conductivity and lowers the $E_{a}$, which may be due to the increase in the electron hole conduction ascribed to the redox behaviour of $\mathrm{Tb}$ and $\mathrm{Co}^{[7 \mathrm{a}]}$.

Figure 4 shows the conductivity dependence on the $\mathrm{pO}_{2}$ for the doped ceria dense bars at $1073 \mathrm{~K}$. The studied range of $\mathrm{pO}_{2}$ includes from oxidant $(0.21-1 \mathrm{~atm})$ to moderately reducing atmospheres $\left(10^{-5}-0.21 \mathrm{~atm}\right)$, where the $\mathrm{Ce}^{4+}$ does not reduce to $\mathrm{Ce}^{3+}$ as it has been demonstrated that this reaction initiates at oxygen partial pressures lower than $10^{-}$ ${ }^{10}$ atm ${ }^{[7 b-d, 14]}$. Except for $\mathrm{Tb}$ and $\mathrm{Pr}$, all the materials show mainly ionic conductivity behaviour, which is independent on $\mathrm{pO}_{2}$. Tb and $\mathrm{Pr}$ doped ceria present a dependency on $\mathrm{pO}_{2}{ }^{-1 / 6}$ attributed to the dopant reduction as $\mathrm{pO}_{2}$ decreases ${ }^{[7 \mathrm{~b}]}$. Even though the conductivity is mainly ionic in these oxidizing conditions, the multiple oxidation state of some dopants makes the ionic conductivity $\mathrm{pO}_{2}$ dependent and adds an electronic contribution due to the introduction of redox couples in the band gap of ceria (region not observed in single-oxidation-state acceptor doped systems such as Er and Gd).

The stability of the doped ceria catalysts has been studied by thermogravimetry under continuous flow of air with $5 \% \mathrm{CO}_{2}$. Figure 5 shows the mass evolution of $\mathrm{Ce}_{0.9} \mathrm{~Tb}_{0.1} \mathrm{O}_{2-}$ $\delta, \mathrm{Ce}_{0.8} \mathrm{~Tb}_{0.2} \mathrm{O}_{2-\delta}, \mathrm{Ce}_{0.8} \mathrm{Er}_{0.1} \mathrm{~Tb}_{0.1} \mathrm{O}_{2-\delta}$ and $\mathrm{Ce}_{0.9} \mathrm{Er}_{0.1} \mathrm{O}_{2-\delta}$ samples together with the evolution of a highly-permeable perovskite, i.e., BSCF. Carbonates are generally formed (mass increase) in the range from 973 to $1073 \mathrm{~K}$ and decompose (mass decrease) at higher temperatures (above $\sim 1123 \mathrm{~K}$ ), as it can be observed for the BSCF measurement. Ceria catalysts presents a negligible formation of carbonates while it is also detected a mass loss in Tb containing compounds, which is ascribed to oxygen release at temperatures above $700 \mathrm{~K}$. All the ceria catalysts were stable under reducing and $\mathrm{CO}_{2}$ containing atmospheres at high temperatures in contrast with the instability observed for $\mathrm{Ba}$ - and Sr-containing perovskites.

\subsection{Oxygen permeation measurements}

$\mathrm{J}\left(\mathrm{O}_{2}\right)$ was determined in the temperature range of 923-1273 K. Figure 6 collects oxygen permeation data in an Arrhenius plot obtained using Ar and diluted methane (85/15 vol.) as sweep gas for the reference BSCF membrane (bare membrane reactor with polished surface), and a BSCF membrane modified with a catalytic layer made of $\mathrm{Ce}_{0.8} \mathrm{Gd}_{0.2} \mathrm{O}_{2-\delta}$. In both samples, $\mathrm{J}\left(\mathrm{O}_{2}\right)$ increases with the temperature as expected. Two different temperature domains become evident as a change in the slope of the curve with an increasing temperature. Moreover, the catalytic membrane activation has been therefore effective at increasing $\mathrm{J}\left(\mathrm{O}_{2}\right)$, specially at low temperature. Oxygen permeation flux is 2.3-fold increased when diluted methane (85/15 vol.) is used as sweep gas 
(Figure 6b). This aspect was expected due to the increase in the separation driving force, i.e., $\log \mathrm{pO}_{2}$ (air) $/ \mathrm{pO}_{2}$ (sweep) from 0.90 to $4.02^{1}$ when diluted methane is used as sweep gas. Furthermore, at low temperatures a decrease in activation energy has also been observed when diluted methane was used as sweep gas. The $\mathrm{E}_{\mathrm{a}}$ values obtained were $65.3 \mathrm{~kJ} / \mathrm{mol}$ and $47.6 \mathrm{~kJ} / \mathrm{mol}$ for bare $\mathrm{BSCF}$ membrane and the activated membrane (ceria coating on BSCF membrane) correspondingly.

The apparent activation energies for oxygen transport process (Table 2, argon sweep) changed as a function of the temperature, indicating that either the rate determining mechanism is modified (e.g. phase transition alters bulk diffusion) or another step becomes rate limiting according to the temperature range investigated. The results suggest that the activation energies at high temperatures remained close to the value observed for bare BSCF membrane ( $\sim 30 \mathrm{~kJ} / \mathrm{mol})$, which is typical of bulk oxygen-ionic diffusion through $\mathrm{BSCF}$ perovskite crystal lattice. In fact, $\mathrm{E}_{\mathrm{a}}$ for oxygen surface exchange rate is higher than for the oxygen ions diffusion; so at low temperature range, the oxygen permeation process is mainly rate-determined by the slow oxygen surface exchange kinetics ${ }^{[2 f, 3-4,15]}$. In the latter case, the surface activation of the membrane using a CGO porous coating results in an important enhancement of $\mathrm{J}\left(\mathrm{O}_{2}\right)$, which stems from the enlarged surface area available for the surface exchange and the intrinsic catalytic activity of doped ceria. As a consequence, the catalytic membrane modification leads to lower activation energy at low temperature range, approaching the $\mathrm{E}_{\mathrm{a}}$ ascribed to bulk diffusion.

\subsection{ODHE performance}

The catalytic results in the ODHE reaction (ethylene selectivity as a function of ethane conversion at $1123 \mathrm{~K}$ ) are presented in Figure 7 for membrane reactors modified with different doped cerias. Different experiments were performed by keeping the residence time constant and changing the ethane concentration in the reaction mixture. In a previous study, we obtained that $\mathrm{X}_{\mathrm{C} 2 \mathrm{H} 6}$ increased with the reaction temperature while the selectivity decreased slightly and remained always at high values for a given feed composition ${ }^{[2 c]}$. A systematic study of the effect of operating conditions on BSCF-MR for the oxidative dehydrogenation of ethane is reported elsewhere ${ }^{[2 \mathrm{~d}]}$. Among the different compositions of $\mathrm{Ce}_{1-\mathrm{x}} \mathrm{Ln}_{\mathrm{x}} \mathrm{O}_{2-\delta}$ considered as catalytic coating (Figure 7), the best results are obtained with the materials with $10 \% \mathrm{~Tb}, 10 \% \operatorname{Pr}$ and a mixture comprising $10 \% \mathrm{~Tb}$ and $10 \% \mathrm{Er}$.

Figure 8 shows the SEM morphologies of catalytic modified BSCF-MR after ODHE test. Even though some pores become visible on the cross-section of the membrane, they are proved to be closed pores by helium leakage test. The catalytic coatings have an open microstructure with macropores and a homogeneous thickness, which was

\footnotetext{
${ }^{1}$ Here, it is assumed that the permeate $p O_{2}$ corresponds to the sweep gas (diluted methane). For the Wagner equation integration, it is also assumed that ionic conductivity does not depends significantly on $\mathrm{pO}_{2}$ and this is negligible with respect to the electronic conductivity.
} 
determined to be $\sim 15 \mu \mathrm{m}$ from SEM image. As said above, all doped-ceria catalysts were stable under reducing and $\mathrm{CO}_{2}$ containing atmospheres at high temperatures, and the integrity of all catalytic porous layers was conserved during the whole reaction tests, as deduced by SEM analysis.

The proper surface modification of the BSCF-MR with a doped-ceria catalyst has allowed increasing the ethylene yield $\sim 11 \%\left(\mathrm{Y}_{\mathrm{C} 2 \mathrm{H} 4} \sim 81.3 \%\right.$ at $\left.7.5 \% \mathrm{C}_{2} \mathrm{H}_{4}\right)$ compared to the bare membrane with polished surface. Furthermore, the raise in catalytic activity for modified BSCF membranes is just accompanied by a slight fall in $\mathrm{S}_{\mathrm{C} 2 \mathrm{H} 4}$. Ethylene is the main reaction product although $\mathrm{H}_{2}, \mathrm{CO}_{\mathrm{x}}, \mathrm{CH}_{4}$ and $\mathrm{C}_{4}$-hydrocarbons are also observed in minor amounts in the products gas stream. Moreover, the oxygen concentration in the products gas stream was less than $40 \mathrm{ppm}$ in the whole range of operating conditions studied.

The improvement of ODHE performance (ethylene yield) observed due to the doping with $\mathrm{Pr}$ or $\mathrm{Tb}$ in ceria-based catalysts (i.e., $\mathrm{Ce}_{0.9} \mathrm{Pr}_{0.1} \mathrm{O}_{2-\delta}$ or $\mathrm{Ce}_{0.9} \mathrm{~Tb}_{0.1} \mathrm{O}_{2-\delta}$ as catalytic coating) is due to the lower $\mathrm{S}_{\mathrm{COx}}$ and $\mathrm{S}_{\mathrm{C} 4}$ with respect to the other catalytic layers (Table 3 ). The catalytic behavior of $\mathrm{Ce}_{1-\mathrm{x}} \mathrm{Ln}_{\mathrm{x}} \mathrm{O}_{2-\delta}$ for ODHE strongly depends on the redox activity of these catalysts and the presence of these multivalent cations ( $\operatorname{Pr}$ and $\mathrm{Tb}$ ), would have a direct impact on the redox activity of ceria, specifically by modifying the nature and surface concentration of oxygen species. Additionally, the concentration of vacancies, i.e. oxygen non-stoichiometry, in the oxide is an important factor, since surface oxygen vacancies are active sites in oxidation reactions. Assuming a Mars-van Krevelen type kinetics ${ }^{[8]}$ for this reaction network, the doped ceria catalyst would operate in redox cycles, being reduced by the hydrocarbon and oxidized by mobile lattice oxygen diffusing from the MIEC membrane:

Reactant $+x \mathrm{O}-\square \rightarrow$ Products $+x \square$

$x \square+x$ O-latice $\rightarrow x$ O- $\square$

where $\square$ represents an active site.

However, when the ODHE reaction is carried out at high temperatures, olefins are not exclusively produced through catalytic conversion and a certain contribution of gasphase reaction takes place. In a previous work ${ }^{[6]}$ the contribution of the gas-phase reaction was evaluated by conducting the same catalytic experiment at $1123 \mathrm{~K}$ but using an inert gastight catalyst-free $\mathrm{Al}_{2} \mathrm{O}_{3}$ membrane (instead of a MIEC membrane). Therefore, no oxygen permeated through the membrane into the reaction side. This experiment showed that the lack of oxygen in the reaction chamber leads to the rapid formation of carbon deposits while, if oxygen was co-fed, the ethylene yield decreases due to the formation of COx. For instance, an ethylene yield of $63 \%$ was reached when $0.5 \%$ oxygen and $7.5 \%$ ethane were co-fed. Nevertheless, the better performance of catalytic MIEC membrane reactors was confirmed by the higher ethylene yield, and the 
lower selectivity towards $\mathrm{COx}$ and $\mathrm{C}_{3}{ }^{+}$products. The reaction network is very complex and may entail several consecutive and parallel steps. Thermal dehydrogenation (evidenced by the hydrogen formation) may occur in parallel with heterogeneous oxidative hydrogenation, while the catalyst may eventually play the additional role to facilitate the generation of radicals. The membrane role is to supply oxygen ion through the solid state conducting catalyst, promoting the oxidative dehydrogenation but also the $\mathrm{COx}$ and $\mathrm{H}_{2}$ oxidation.

Figure 9a collects the catalytic results reached using catalytic coatings based on $\mathrm{Ce}_{0.9} \mathrm{~Tb}_{0.1} \mathrm{O}_{2-\delta}, \mathrm{Ce}_{0.8} \mathrm{~Tb}_{0.2} \mathrm{O}_{2-\delta}$ and $\mathrm{Ce}_{0.8} \mathrm{~Tb}_{0.2} \mathrm{O}_{2-\delta}{ }^{+} 2 \%$ Co. Figure 9b shows the SEM pictures of fracture cross-section for three catalytic layers of terbium-doped ceria after ODHE reaction test. The ethylene yield increases with the amount of terbium incorporated in the lattice of ceria. $\mathrm{Ce}_{0.8} \mathrm{~Tb}_{0.2} \mathrm{O}_{2-\delta}$ presents a higher number of oxygen vacancies that increase the oxygen transport and surface adsorption properties while it additionally contributes to the structural strain, which may be related with the chemical reactivity of the material ${ }^{[17]}$. Actually, the highest strains (Table 1) in the studied series were observed for $\mathrm{Ce}_{0.8} \mathrm{~Tb}_{0.2} \mathrm{O}_{2-\delta}$ and $\mathrm{Ce}_{0.8} \mathrm{~Tb}_{0.2} \mathrm{O}_{2-\delta} \quad 2 \% \mathrm{Co}$ (-16.5 and -19.5 a.u., respectively).

The incorporation of Co cations in to the $\mathrm{Ce}_{1-\mathrm{x}} \mathrm{Tb}_{\mathrm{x}} \mathrm{O}_{2-\delta}$ system is reported to favor the reducibility of $\mathrm{Tb}^{4+}$ to $\mathrm{Tb}^{3+}$ at high temperatures and induce changes in the oxide conduction band. Specifically, TPD measurements demonstrate that the addition of either $\mathrm{Co}$ or higher amount $\mathrm{Tb}$ allows increasing the oxygen release, i.e., the material reducibility ${ }^{[7 \mathrm{a}]}$. On the other hand, the ethylene yield obtained with $\mathrm{Ce}_{0.8} \mathrm{~Tb}_{0.2} \mathrm{O}_{2 \text { - }}$ ${ }_{\delta}+2 \% \mathrm{Co}$ is worse with regard to $\mathrm{Ce}_{0.8} \mathrm{~Tb}_{0.2} \mathrm{O}_{2-\delta}$ and this may be due to (1) the smaller specific surface arising from the greater particle size observed for Co sintered samples $^{[7 \mathrm{a}]}$, which results in a slightly lower conversion (Table 3 ) and (2) the promotion of catalytic combustion of hydrocarbons ${ }^{[18]}$ by surface Co species. This last effect is very small since the $\mathrm{CO}_{\mathrm{x}}$ selectivity increases only a bit, as inferred from the results presented in Table 3. On the other hand, the improved oxide reducibility and electronic conductivity does not seem to have any clear effect on the catalytic activity. Finally, the use of $\mathrm{Ce}_{0.8} \mathrm{~Tb}_{0.2} \mathrm{O}_{2-\delta}$ as catalytic layer enables to reach the highest ethylene selectivity, while it showed low $\mathrm{CO}_{\mathrm{X}}$ and $\mathrm{C}_{4}$ selectivities compared to the others Tb-doped ceria catalytic coatings.

Several previous works illustrate that dense MIEC membrane reactors are very appealing for the ODHE process. This concept includes process intensification since both, separation (oxygen-ion diffusion through the membrane lattice) and reaction are included in the same unit. A disk-shaped BSCF membrane reactor ${ }^{[2 \mathrm{e}]}$ at $777^{\circ} \mathrm{C}$ using 25 $\% \mathrm{v} / \mathrm{v}$ of $\mathrm{C}_{2} \mathrm{H}_{6}$ in the feed stream allowed reaching a $\mathrm{Y}_{\mathrm{C} 2 \mathrm{H} 4} \sim 75 \%$ when the membrane surface was modified with $\mathrm{Pd}$ nano-clusters. Moreover, a $73 \%$ was achieved $\mathrm{Y}_{\mathrm{C} 2 \mathrm{H} 4}$ when the membrane surface was activated using a thin layer of $\mathrm{V} / \mathrm{MgO}$. Akin and Lin [2a] employed a tubular $\mathrm{Bi}_{1.5} \mathrm{Y}_{0.3} \mathrm{SmO}_{3}$ membrane at $875^{\circ} \mathrm{C}$ and $10 \%$ of $\mathrm{C}_{2} \mathrm{H}_{6}$ in the feed stream and a $\mathrm{Y}_{\mathrm{C} 2 \mathrm{H} 4} \sim 56 \%$ (per pass) was reached. Yang et al. ${ }^{[2 \mathrm{~g}]}$ used a dense MIEC 
( $\left.\mathrm{Ba}_{0.5} \mathrm{Sr}_{0.5} \mathrm{Co}_{0.8} \mathrm{Fe}_{0.2} \mathrm{O}_{3-\delta}\right)$ as membrane in a co-feed reactor reaching an ethylene selectivity of $80 \%$ at $84 \%$ ethane conversion. Caro et al. ${ }^{[2 \mathrm{~b}]}$ reported an ethylene yield of $43 \%$ and ethylene selectivity of $67 \%$ using a dense perovskite hollow-fiber $\mathrm{BaCo}_{\mathrm{x}} \mathrm{Fe}_{\mathrm{y}} \mathrm{Zr}_{\mathrm{Z}} \mathrm{O}_{3-\delta}$ membrane and a commercial dehydrogenation catalyst $\left(\mathrm{Cr}_{2} \mathrm{O}_{3}\right.$ on $\mathrm{Ca}$ aluminate) as packed-bed, at $725^{\circ} \mathrm{C}$ and $30 \% \mathrm{v} / \mathrm{v}$ of $\mathrm{C}_{2} \mathrm{H}_{6}$. Wang et al. ${ }^{[2 \mathrm{f}]}$ investigated ODHE using a dense BSCF membrane at $850{ }^{\circ} \mathrm{C}$ and $10 \% \mathrm{v} / \mathrm{v}$ of $\mathrm{C}_{2} \mathrm{H}_{6}$ in the feed stream, reaching an ethylene selectivity of $67.4 \%$ at $80 \%$ ethane conversion. Nevertheless, it should be considered the diversity of operating conditions (temperature, contact times), catalysts and reactor configuration in these works.

Finally, a previous work using a BSCF membrane reactor modified with perovskitebased catalytic coatings ${ }^{[6]}$ reached an ethylene yield $(\sim 81 \%)$ in our group. In the present study the use of a $\mathrm{Ce}_{0.8} \mathrm{~Tb}_{0.2} \mathrm{O}_{2-\delta}$ catalytic coating has produced an increase in the ethylene yield (close to $84 \%$ ). These interesting results could be ascribed to the joint use of (1) an oxide-ion conducting membrane and (2) a catalyst containing a redox couple and exhibiting high lattice oxygen anion mobility, which warranties the reoxidation of the reduced catalyst surface. Additionally, the high yields obtained in this kind of catalytic membranes MIEC are attributed to the combination of: $(i)$ high catalytic activity related to the high operating temperature, promoting oxidative and thermal ethane dehydrogenation, and the oxygen species diffusing through the membrane; (ii) control of the oxygen concentration in the gas phase (reaction chamber); and (iii) appropriate fluid dynamics, enabling the right contact between the feed gas stream and membrane/catalyst assembly and the fast evacuation of reaction products.

The catalytic activity towards ODHE of the best ceria coating $\left(\mathrm{Ce}_{0.8} \mathrm{~Tb}_{0.2} \mathrm{O}_{2-\delta}\right)$ found in the previous CMR experiments was evaluated in a conventional fixed bed reactor. Table 4 presents a summary of the catalytic performance at $1123 \mathrm{~K}$ where ethane and oxygen were co-fed using Ar as gas carrier. Catalytic test results at lower temperatures are available in Supporting Material. The ethylene selectivity at $1123 \mathrm{~K}$ is below $78 \%$ regardless of the $\mathrm{O}_{2}$ content in feed. The coke selectivity is around $10 \%$ at low $\mathrm{O}_{2} \%$ while COx selectivity is above $40 \%$ for $2.44 \% \mathrm{O}_{2}$ although the selectivity is always below $65 \%$. Consequently, the highest ethylene yield achieved in this test was $42 \%$. These results evidence that the use of the catalytically-activated MIEC membrane reactor is very effective in the ODHE process, allowing achieving both high ethylene selectivity and ethane conversion in contrast with conventional fixed bed reactors.

\section{4.}

\section{Conclusions}

Oxidative dehydrogenation of ethane has been studied at $1123 \mathrm{~K}$ as a function of ethane concentration in feed on catalytic membrane reactors made of $\mathrm{Ba}_{0.5} \mathrm{Sr}_{0.5} \mathrm{Co}_{0.8} \mathrm{Fe}_{0.2} \mathrm{O}_{3-\delta}$. The membrane surface in the permeate side (reaction chamber) was modified using porous coatings based on rare earth-doped cerias (fluorite structure) deposited by screen printing (coating around $15 \mu \mathrm{m}$ ). Specifically, seven different catalyst based on the 
system $\mathrm{Ce}_{1-\mathrm{x}} \mathrm{Ln}_{\mathrm{x}} \mathrm{O}_{2-\delta}$ ( $\mathrm{x}=0.1$ or $0.2 ; \mathrm{Ln}=\mathrm{Tb}, \mathrm{Pr}, \mathrm{Er}, \mathrm{Gd}$ and $\mathrm{Tb}+\mathrm{Er}$ ) were synthesized by co-precipitation. The ceria catalysts were studied by XRD, SEM, DC-conductivity as a function of oxygen partial pressure and temperature, which illustrates how the different dopants modify the conduction properties, principally oxide ion transport, and the redox behavior, e.g. oxygen vacancy. Moreover, the high-temperature stability in $\mathrm{CO}_{2}$ environment was confirmed using thermogravimetry. The modification of the MIEC membrane allowed increasing the oxygen permeation flux when using both argon and methane as sweep gas in the permeate side.

The use of disk-shaped membranes in the reactor made it possible to prevent the direct contact of gaseous oxygen and hydrocarbons and hence to increase the ethylene. High ethylene yields (up to $~ 84 \%$ ) were obtained using a catalytic coating based on $20 \% \mathrm{~Tb}$ doped ceria and this is attributed to the redox properties of the Tb doped sample in combination with the high concentration of oxygen vacancies, actives sites in the reaction mechanism. The addition of cobalt was not beneficial probably due to the loss of surface are related to the higher sintering activity. However, the understanding of the ODHE fundamental mechanism at high temperature in membrane reactors is still limited. Indeed, the reaction network is very complex and may involve several consecutive and parallel steps. Thermal may take place in parallel with heterogeneous oxidative hydrogenation, while the catalyst may eventually play the additional role to facilitate the generation of radicals. Oxygen supplied from the membrane would regenerate redox sites on the catalyst surface, promoting the heterogeneous ODHE reaction and, in less extent, the oxidation of $\mathrm{H}_{2}$ and deep oxidation of methane to $\mathrm{COx}$.

This membrane reactor system combines a highly permeable oxygen membrane and an active catalytic coating with high redox and $\mathrm{CO}_{2}$ stability. The ceria catalyst allows boosting the oxygen permeation through the promotion of the oxygen exchange reaction. Moreover, the catalyst formulation and the membrane reactor configuration made it possible to achieve very high ethylene yields while maintaining low selectivity towards COx and coke. The high yields obtained in this kind of catalytic membranes are attributed to the combination of: the high catalytic activity; the control of the oxygen concentration in the gas phase (reaction chamber); and the appropriate fluid dynamics, enabling the fast ethylene evacuation.

\section{Acknowledgements}

Financial support by the Spanish Ministry for Science and Innovation (ENE2011-24761 FPI BES-2009-015835 grants), EU through FP7 NASA-OTM Project (NMP3-SL-2009228701), and the Helmholtz Association of German Research Centres through the Helmholtz Alliance MEM-BRAIN (Initiative and Networking Fund) is kindly acknowledged. 


\section{FIGURE CAPTIONS}

Figure 1. Scheme of a cross section of the surface activated BSCF membrane reactor.

Figure 2. (a) $\mathrm{XRD}$ patterns of $\mathrm{Ce}_{1-\mathrm{x}} \mathrm{Ln}_{\mathrm{x}} \mathrm{O}_{2-\delta}$ powders sintered at $1573 \mathrm{~K}$ : (1) $\mathrm{Ce}_{0.8} \mathrm{Gd}_{0.2} \mathrm{O}_{2-\delta} ;$ (2) $\mathrm{Ce}_{0.9} \mathrm{Pr}_{0.1} \mathrm{O}_{2-\delta} ;$ (3) $\mathrm{Ce}_{0.9} \mathrm{Er}_{0.1} \mathrm{O}_{2-\delta} ;$ (4) $\mathrm{Ce}_{0.8} \mathrm{Er}_{0.1} \mathrm{~Tb}_{0.1} \mathrm{O}_{2-\delta} ;$ (5) $\mathrm{Ce}_{0.9} \mathrm{~Tb}_{0.1} \mathrm{O}_{2-\delta} ;$ (6) $\mathrm{Ce}_{0.8} \mathrm{~Tb}_{0.2} \mathrm{O}_{2-\delta} ;$ (7) $\mathrm{Ce}_{0.9} \mathrm{~Tb}_{0.8} \mathrm{O}_{2-\delta}+2 \%$ Co. (b) SEM pictures of $\mathrm{Ce}_{0.8} \mathrm{~Tb}_{0.2} \mathrm{O}_{2-\delta}$ and $\mathrm{Ce}_{0.8} \mathrm{~Tb}_{0.2} \mathrm{O}_{2-\delta}+\mathrm{Co}$ membranes calcined at $1473 \mathrm{~K}$.

Figure 3. Arrhenius plot of the total conductivity in air of different doped cerias measured by DC conductivity.

Figure 4. Total cconductivity as a function of $\mathrm{pO}_{2}$ for different doped cerias (dense bars) at $1073 \mathrm{~K}$.

Figure 5. TG-CO $\mathrm{CO}_{2}$ measurements: mass evolution of $\mathrm{Ce}_{0.9} \mathrm{~Tb}_{0.1} \mathrm{O}_{2-\delta}, \mathrm{Ce}_{0.8} \mathrm{~Tb}_{0.2} \mathrm{O}_{2-\delta}$, $\mathrm{Ce}_{0.8} \mathrm{Er}_{0.1} \mathrm{~Tb}_{0.1} \mathrm{O}_{2-\delta}, \mathrm{Ce}_{0.9} \mathrm{Er}_{0.1} \mathrm{O}_{2-\delta}$ and $\mathrm{BSCF}$ in $5 \% \mathrm{CO}_{2}$ in air (heating ramp $10 \mathrm{~K} / \mathrm{min}$ ).

Figure 6. Arrhenius plots of oxygen permeation flux through different catalytic

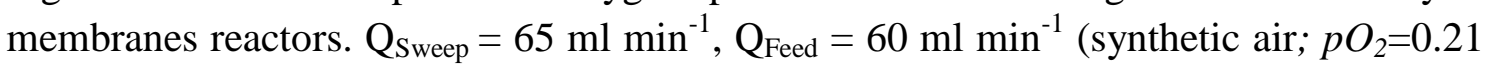
atm). (a) Ar was used as sweep gas; (b) $\mathrm{Ar} / \mathrm{CH}_{4}$ (85/15vol.) was used as sweep gas.

Figure 7. Comparative results on ethylene selectivities at different degrees of ethane conversions derived from the experiments performed with the catalytic modified BSCFMR used in this study. $\mathrm{T}=1123 \mathrm{~K}$, Q Qreaction-side $=400 \mathrm{ml} \mathrm{min}$, ethane diluted with argon; $\mathrm{Q}_{\text {feed-side }}=210 \mathrm{ml} \mathrm{min}^{-1}\left(p O_{2}=0.04 \mathrm{~atm}\right)$.

Figure 8. SEM images of the fracture cross-section of the different doped-ceria catalytic coatings on BSFC membranes after oxygen permeation tests. (a) Bare membrane (polished surface); catalytic coatings: (b) $\mathrm{Ce}_{0.8} \mathrm{Gd}_{0.2} \mathrm{O}_{2-\delta} ;$ (c) $\mathrm{Ce}_{0.9} \mathrm{Pr}_{0.1} \mathrm{O}_{2-\delta}$; (d) $\mathrm{Ce}_{0.9} \mathrm{~Tb}_{0.1} \mathrm{O}_{2-\delta} ;$ (e) $\mathrm{Ce}_{0.9} \mathrm{Er}_{0.1} \mathrm{O}_{2-\delta} ;$ (f) $\mathrm{Ce}_{0.8} \mathrm{Er}_{0.1} \mathrm{~Tb}_{0.1} \mathrm{O}_{2-\delta}$.

Figure 7. (a) Ethylene selectivity vs ethane conversion for experiments performed with BSCF membrane reactors. $\mathrm{Ce}_{1-x} \mathrm{~Tb}_{x} \mathrm{O}_{2-\delta}$ system is considered: $\mathrm{Ce}_{0.9} \mathrm{~Tb}_{0.1} \mathrm{O}_{2-\delta}$; $\mathrm{Ce}_{0.8} \mathrm{~Tb}_{0.2} \mathrm{O}_{2-\delta} ; \mathrm{Ce}_{0.9} \mathrm{~Tb}_{0.8} \mathrm{O}_{2-\delta}+2 \mathrm{~mol} \%$ Co. $\mathrm{T}=1123 \mathrm{~K}$, Q Qreaction side $=400 \mathrm{ml} \mathrm{min}^{-1}$, ethane diluted with argon; $Q_{\text {feed side }}=210 \mathrm{ml} \mathrm{min}^{-1}\left(p O_{2}=0.04 \mathrm{~atm}\right)$. (b) SEM images of the fracture cross-section of the $\mathrm{Ce}_{1-x} \mathrm{~Tb}_{x} \mathrm{O}_{2-\delta}$ based catalytic layers on BSFC membranes after catalytic test.

Figure 8. Catalytic performance of the modified BSCF-MR in the ODHE reaction in terms of ethylene selectivity as a function of ethane conversion. Data for various eatalytic dense membrane reactors reported in literature: (1) Mirodatos et al. ${ }^{[2 \mathrm{e}} ;$; (2) Akin and Lin ${ }^{[2 \mathrm{a}]} ;$; (3) Yang et al. ${ }^{[2 \mathrm{~g}]} ;$ (4) Caro et al. ${ }^{[2 \mathrm{~b}]} ;$ (5) Wang et al. ${ }^{[2 f]}=$ 


\section{TABLES}

Table 1. Cell parameter, strain, non-stoichiometry in air at room temperature and 1023 $\mathrm{K}$, total conductivity at $1073 \mathrm{~K}$ and activation energies for $\mathrm{Ce}_{1-\mathrm{x}} \mathrm{Ln}_{\mathrm{x}} \mathrm{O}_{2-\delta} . \mathrm{a}_{\text {error }}= \pm 0.0002$ $(\AA)$.

\begin{tabular}{|c|c|c|c|c|c|c|c|}
\hline Composition & $\begin{array}{c}\mathrm{a}_{\mathrm{RT}} \\
{[\AA]}\end{array}$ & $\begin{array}{c}\mathrm{a}_{1123 \mathrm{~K}} \\
{[\AA]}\end{array}$ & $\begin{array}{c}\text { strain } \\
{[\mathrm{a} . \mathrm{u} .]}\end{array}$ & $\delta_{298 \mathrm{~K}}$ & $\delta_{1123 \mathrm{~K}}$ & $\begin{array}{c}\sigma_{1073 \mathrm{~K}} \\
{\left[\mathrm{~S} \cdot \mathrm{cm}^{-1}\right]}\end{array}$ & $\begin{array}{c}\mathrm{E}_{\mathrm{a}} \\
{[\mathrm{kJ} / \mathrm{mol}]}\end{array}$ \\
\hline $\mathrm{Ce}_{0.9} \mathrm{~Tb}_{0.1} \mathrm{O}_{2-\delta}$ & 5.3994 & 5.4625 & -9.17 & 0.020 & 0.045 & 0.018 & $106.1 \pm 0.9$ \\
\hline $\mathrm{Ce}_{0.8} \mathrm{~Tb}_{0.2} \mathrm{O}_{2-\delta}$ & 5.3918 & 5.4725 & -16.54 & 0.047 & 0.092 & 0.035 & $84.2 \pm 0.2$ \\
\hline $\mathrm{Ce}_{0.8} \mathrm{~Tb}_{0.2} \mathrm{O}_{2-\delta}+\mathrm{Co} 2 \%$ & 5.3852 & 5.4661 & -19.5 & 0.046 & 0.084 & 0.048 & $81.7 \pm 0.1$ \\
\hline $\mathrm{Ce}_{0.8} \mathrm{Gd}_{0.2} \mathrm{O}_{2-\delta}$ & 5.4225 & 5.4784 & 7.9 & 0.1 & 0.1 & 0.066 & $74.5 \pm 0.1$ \\
\hline $\mathrm{Ce}_{0.9} \mathrm{Pr}_{0.1} \mathrm{O}_{2-\delta}$ & 5.4071 & 5.4771 & 1.29 & & & 0.047 & $86.8 \pm 1.0$ \\
\hline $\mathrm{Ce}_{0.9} \mathrm{Er}_{0.1} \mathrm{O}_{2-\delta}$ & 5.4055 & 5.4586 & -3.6 & 0.05 & 0.05 & 0.049 & $79.6 \pm 0.2$ \\
\hline $\mathrm{Ce}_{0.8} \mathrm{Er}_{0.1} \mathrm{~Tb}_{0.1} \mathrm{O}_{2-\delta}$ & 5.3980 & & -12.8 & 0.063 & 0.097 & 0.068 & $95.5 \pm 0.3$ \\
\hline
\end{tabular}


Table 2. Estimation of the activation energy $\left(\mathrm{E}_{\mathrm{a}}, \mathrm{kJ} / \mathrm{mol}\right)^{*}$ with regard to oxygen permeation flux are shown (Ar as sweep gas). Catalytic coatings based on Ln-doped ceria were used on bulk BSCF membrane. The catalytic coatings were calcined at 1323 $K$.

\begin{tabular}{|l|c|c|c|}
\hline \multicolumn{2}{|c|}{ Catalytic Layer } & \multicolumn{2}{c|}{$\mathbf{E}_{\mathbf{a}}[\mathbf{k J} / \mathbf{m o l}]$} \\
\hline \multicolumn{1}{|c|}{ Composition } & Thickness $[\mu \mathrm{m}]$ & High $\mathrm{T}$ & Low T \\
\hline Bare BSCF membrane & --- & $32.4 \pm 1.2$ & $79.9 \pm 3.5$ \\
\hline $\mathrm{Ce}_{0.9} \mathrm{Pr}_{0.1} \mathrm{O}_{2-\delta}$ & 15 & $29.2 \pm 1.9$ & $49.5 \pm 2.6$ \\
\hline $\mathrm{Ce}_{0.9} \mathrm{Er}_{0.1} \mathrm{O}_{2-\delta}$ & 17 & $35.5 \pm 2.1$ & $50.4 \pm 1.9$ \\
\hline $\mathrm{Ce}_{0.9} \mathrm{~Tb}_{0.1} \mathrm{O}_{2-\delta}$ & 14 & $32.3 \pm 1.3$ & $50.0 \pm 2.3$ \\
\hline $\mathrm{Ce}_{0.8} \mathrm{~Tb}_{0.1} \mathrm{Er}_{0.1} \mathrm{O}_{2-\delta}$ & 16 & $25.8 \pm 2.3$ & $62.4 \pm 1.7$ \\
\hline $\mathrm{Ce}_{0.8} \mathrm{Gd}_{0.2} \mathrm{O}_{2-\delta}$ & 12 & $30.2 \pm 1.5$ & $56.3 \pm 2.7$ \\
\hline $\mathrm{Ce}_{0.8} \mathrm{~Tb}_{0.2} \mathrm{O}_{2-\delta}$ & 14 & $29.4 \pm 0.9$ & $55.7 \pm 3.1$ \\
\hline $\mathrm{Ce}_{0.8} \mathrm{~Tb}_{0.2} \mathrm{O}_{2-\delta}+2 \% \mathrm{Co}$ & 16 & $32.1 \pm 1.4$ & $54.3 \pm 2.8$ \\
\hline
\end{tabular}

$* \pm 95 \%$ C.I. 
Table 3. Catalytic performance of the different BSCF membrane reactors is collected. T=1123 K, ethane diluted in Ar (7.5/92.5 vol.)

\begin{tabular}{|c|c|c|c|c|c|c|c|c|}
\hline \multicolumn{4}{|c|}{ Catalytic layer } & \multicolumn{5}{|c|}{ ODHE performance } \\
\hline \multirow[t]{2}{*}{ Composition } & \multirow[t]{2}{*}{ Thickness $[\mu \mathrm{m}]$} & \multirow[t]{2}{*}{$\mathrm{Y}_{\mathrm{C} 2 \mathrm{H} 4}[\%]$} & \multirow[t]{2}{*}{$\mathrm{X}_{\mathrm{C} 2 \mathrm{H} 6}[\%]$} & \multicolumn{4}{|c|}{ Selectivity [\%] } & \multirow[t]{2}{*}{$\begin{array}{c}\mathrm{C}_{2} \mathrm{H}_{4} \text { productivity } \\
{\left[\mathrm{ml} / \mathrm{min} \mathrm{cm}^{2}\right]}\end{array}$} \\
\hline & & & & $\mathrm{C}_{2} \mathrm{H}_{4}$ & $C O_{X}$ & $C_{4}$ & $\mathrm{CH}_{4}$ & \\
\hline Bare BSCF membrane & --- & 73.1 & 87.8 & 83.3 & 3.7 & 3.4 & 9.3 & 28.7 \\
\hline $\mathrm{Ce}_{0.9} \mathrm{Pr}_{0.1} \mathrm{O}_{2-\delta}$ & 15 & 77.3 & 84.1 & 91.9 & 0.8 & 5.9 & 1.1 & 30.3 \\
\hline $\mathrm{Ce}_{0.9} \mathrm{Er}_{0.1} \mathrm{O}_{2-\delta}$ & 17 & 75.6 & 82.7 & 91.4 & 1.1 & 6.1 & 1.3 & 29.6 \\
\hline $\mathrm{Ce}_{0.9} \mathrm{~Tb}_{0.1} \mathrm{O}_{2-\delta}$ & 14 & 81.3 & 89.0 & 91.4 & 0.8 & 5.8 & 1.6 & 31.9 \\
\hline $\mathrm{Ce}_{0.8} \mathrm{~Tb}_{0.1} \mathrm{Er}_{0.1} \mathrm{O}_{2-\delta}$ & 16 & 77.3 & 83.9 & 92.0 & 1.0 & 5.8 & 1.1 & 30.3 \\
\hline $\mathrm{Ce}_{0.8} \mathrm{Gd}_{0.2} \mathrm{O}_{2-\delta}$ & 12 & 73.9 & 81.0 & 91.2 & 1.3 & 5.9 & 1.4 & 29.0 \\
\hline $\mathrm{Ce}_{0.8} \mathrm{~Tb}_{0.2} \mathrm{O}_{2-\delta}$ & 14 & 82.5 & 89.2 & 92.5 & 0.7 & 5.1 & 1.5 & 32.4 \\
\hline $\mathrm{Ce}_{0.8} \mathrm{~Tb}_{0.2} \mathrm{O}_{2-\delta}+2 \%$ mol. Co & 16 & 81.9 & 89.3 & 91.7 & 1.1 & 5.4 & 1.6 & 32.1 \\
\hline
\end{tabular}


Table 4. Catalytic performance of the $\mathrm{Ce}_{0.8} \mathrm{~Tb}_{0.2} \mathrm{O}_{2-\delta}$ catalyst in a fixed bed reactor. $\mathrm{T}=1123 \mathrm{~K}$, ethane diluted in $\operatorname{Ar}(7.5 \% 1$.)

\begin{tabular}{|c|c|c|c|c|c|c|c|}
\hline \multirow[b]{2}{*}{$\mathrm{O} 2 \%$ in Feed } & \multirow[b]{2}{*}{$\mathrm{Y}_{\mathrm{C} 2 \mathrm{H} 4}[\%]$} & \multirow[b]{2}{*}{$\mathrm{X}_{\mathrm{C} 2 \mathrm{H} 6}[\%]$} & \multicolumn{5}{|c|}{ Selectivity [\%] } \\
\hline & & & $\mathrm{C}_{2} \mathrm{H}_{4}$ & $\mathrm{CO}_{\mathrm{x}}$ & $\mathrm{C}_{3}^{+}$ & $\mathrm{CH}_{4}$ & coke \\
\hline 0.26 & 42.2 & 54.6 & 77.2 & 7.2 & 2.4 & 2.0 & 11.2 \\
\hline 0.42 & 40.7 & 52.2 & 78.0 & 11.5 & 1.9 & 1.8 & 6.8 \\
\hline 1.23 & 34.2 & 56.5 & 60.6 & 33.6 & 1.1 & 1.4 & 3.3 \\
\hline 2.44 & 35.8 & 64.9 & 55.1 & 40.7 & 1.2 & 1.3 & 1.8 \\
\hline
\end{tabular}




\section{REFERENCES}

[1] aM. M. Bhasin, J. H. McCain, B. V. Vora, T. Imai, P. R. Pujadó, Applied Catalysis A: General 2001, 221, 397-419; bT. Blasco, J. M. L. Nieto, Applied Catalysis A:General 1997, 157, 117-142.

[2] aF. T. Akin, Y. S. Lin, Journal of Membrane Science 2002, 209, 457-467; bO. Czuprat, S. Werth, S. Schirrmeister, T. Schiestel, J. Caro, ChemCatChem 2009, 1, 401-405; cM. P. Lobera, S. Escolástico, J. M. Serra, ChemCatChem 2011, 3, 1503-1508; dM. P. Lobera, S. Valero, J. M. Serra, S. Escolástico, E. Argente, V. Botti, Chemical Engineering Science 2011, 66, 6308-6312; eM. RebeilleauDassonneville, S. Rosini, A. C. van Veen, D. Farrusseng, C. Mirodatos, Catalysis Today 2005, 104, 131-137; fH. H. Wang, Y. Cong, W. S. Yang, Catalysis Letters 2002, 84, 101-106; gW. Yang, H. Wang, X. Zhu, L. Lin, Topics in Catalysis 2005, 35, 155-167; hF. Cavani, N. Ballarini, A. Cericola, Catalysis Today 2007, 127, 113-131; iR. K. Grasselli, Catalysis Today 1999, 49, 141-153.

[3] J. Sunarso, S. Baumann, J. M. Serra, W. A. Meulenberg, S. Liu, Y. S. Lin, J. C. D. da Costa, Journal of Membrane Science 2008, 320, 13-41.

[4] Z. Shao, W. Yang, Y. Cong, H. Dong, J. Tong, G. Xiong, Journal of Membrane Science 2000, 172, 177-188.

[5] aS. Baumann, J. M. Serra, M. P. Lobera, S. Escolástico, F. Schulze-Küppers, W. A. Meulenberg, Journal of Membrane Science 2011, 377, 198-205; bA. Leo, S. Liu, J. C. Diniz da Costa, Journal of Membrane Science 2009, 340, 148-153; cA. Leo, S. Smart, S. Liu, J. C. Diniz da Costa, Journal of Membrane Science 2011, 368, 64-68.

[6] M. P. Lobera, S. Escolastico, J. Garcia-Fayos, J. M. Serra, ChemSusChem 2012.

[7] aM. a. Balaguer, C. Solís, J. M. Serra, Chemistry of Materials 2011, 23, 23332343; bS. R. Bishop, T. S. Stefanik, H. L. Tuller, Physical Chemistry Chemical Physics 2011, 13, 10165-10173; cD. P. Fagg, J. R. Frade, V. V. Kharton, I. P. Marozau, Journal of Solid State Chemistry 2006, 179, 1469-1477; dD. P. Fagg, S. García-Martin, V. V. Kharton, J. R. Frade, Chemistry of Materials 2008, 21, 381-391.

[8] P. Mars, D. W. van Krevelen, Chemical Engineering Science 1954, 3, Supplement 1, 41-59.

[9] M. P. Lobera, J. M. Serra, S. P. Foghmoes, M. Søgaard, A. Kaiser, Journal of Membrane Science 2011, 385-386, 154-161.

[10] J. D. Nicholas, L. C. De Jonghe, Solid State Ionics 2007, 178, 1187-1194.

[11] M. a. Balaguer, C. Solís, J. M. Serra, Journal of Physical Chemistry C 2012.

[12] J. M. Serra, V. B. Vert, O. Buechler, W. A. Meulenberg, H. P. Buchkremer, Chemistry of Materials 2008, 20, 3867-3875.

[13] S. Omar, E. D. Wachsman, J. L. Jones, J. C. Nino, Journal of the American Ceramic Society 2009, 92, 2674-2681.

[14] aC. Chatzichristodoulou, P. V. Hendriksen, A. Hagen, Journal of The Electrochemical Society 2010, 157, B299-B307; bKeith L. Duncan, Yanli Wang, Sean R. Bishop, Fereshteh Ebrahimi, E. D. Wachsman, Journal of Applied Physics 2007, 101, 044906.

[15] J. Vente, S. McIntosh, W. Haije, H. Bouwmeester, Journal of Solid State Electrochemistry 2006, 10, 581-588.

[16] Y. Liu, X. Tan, K. Li, Catalysis Reviews 2006, 48, 145-198.

[17] X. Wang, J. C. Hanson, G. Liu, J. A. Rodriguez, A. Iglesias-Juez, M. FernandezGarcia, The Journal of Chemical Physics 2004, 121, 5434-5444. 
[18] T.-c. Xiao, S.-f. Ji, H.-t. Wang, K. S. Coleman, M. L. H. Green, Journal of Molecular Catalysis A: Chemical 2001, 175, 111-123. 
Figure 1

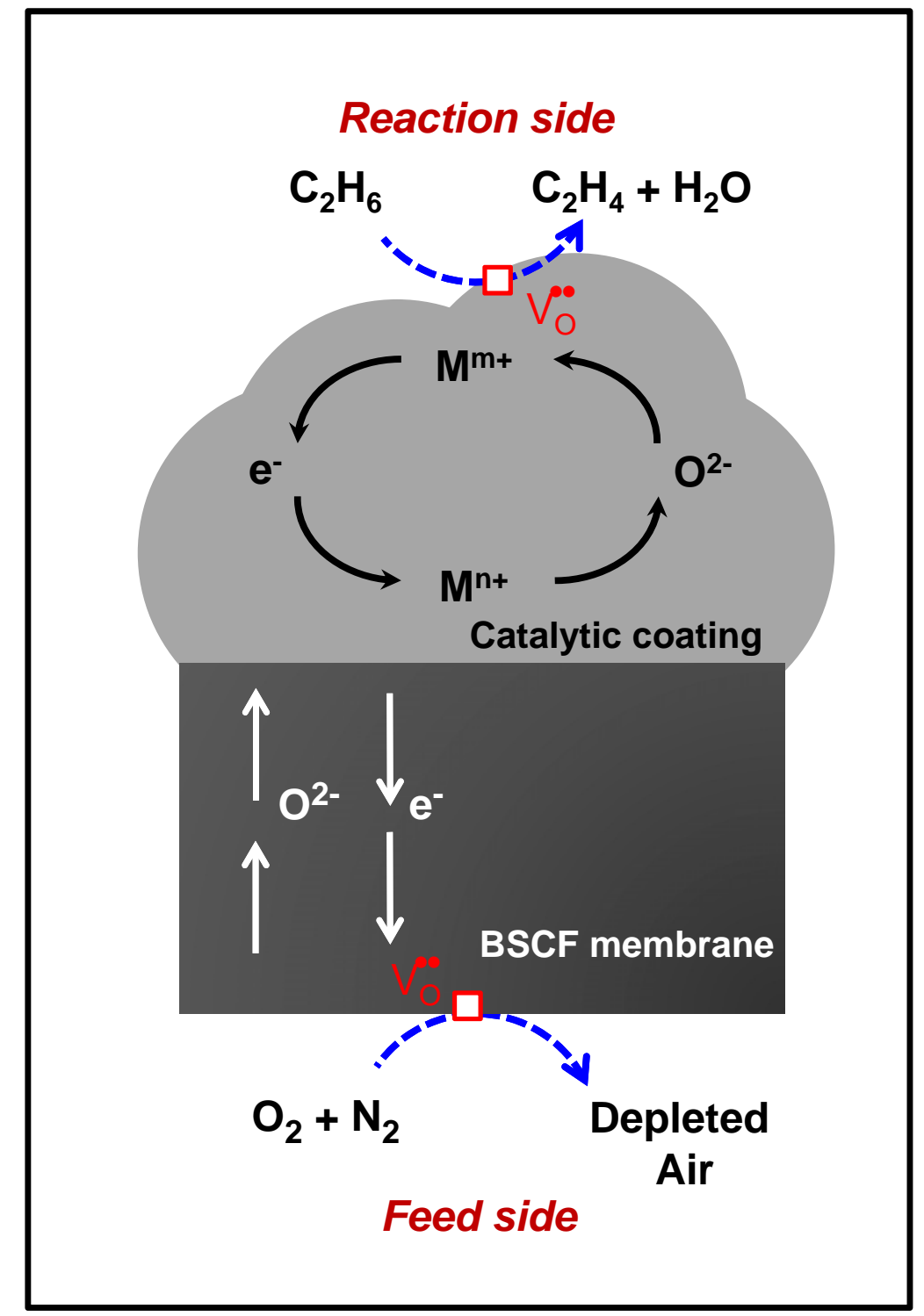


Figure 2

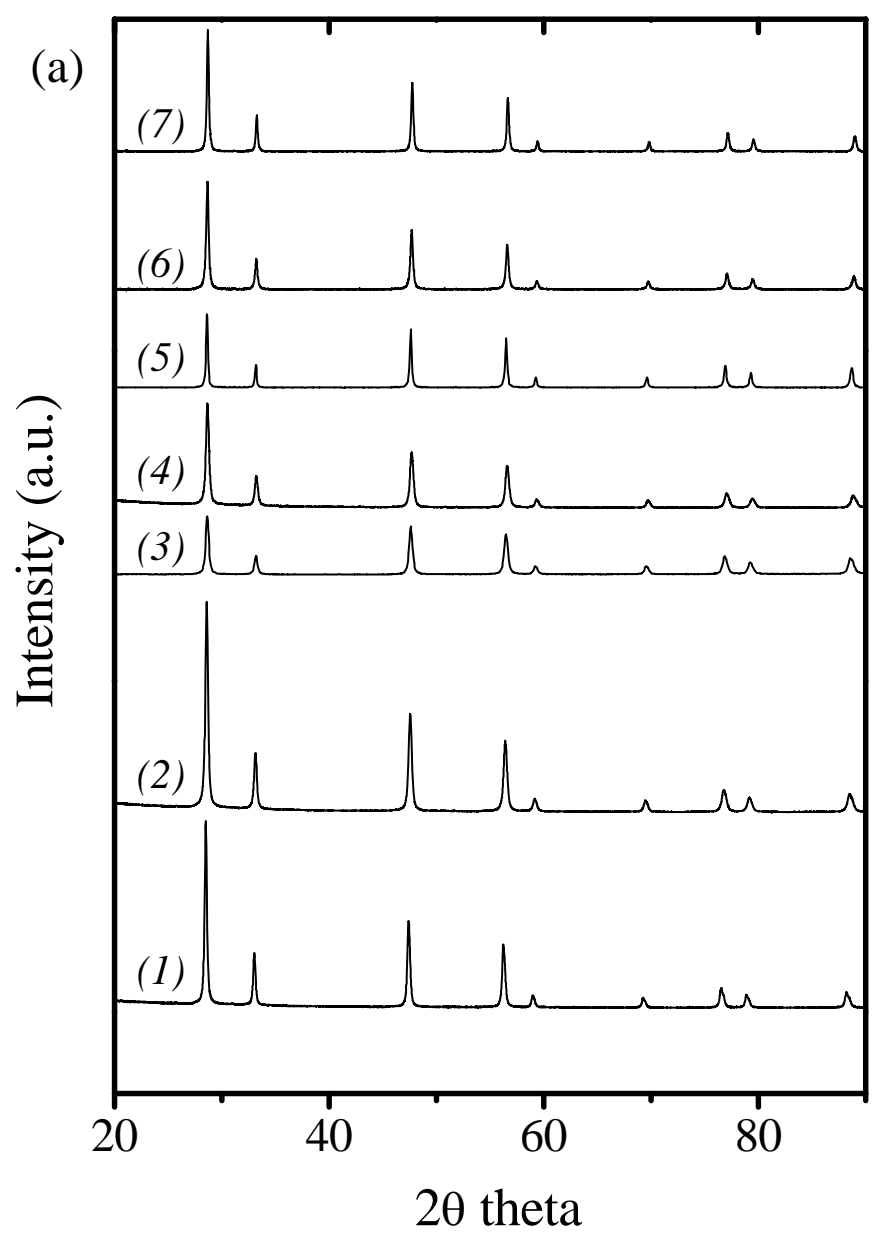

(b)
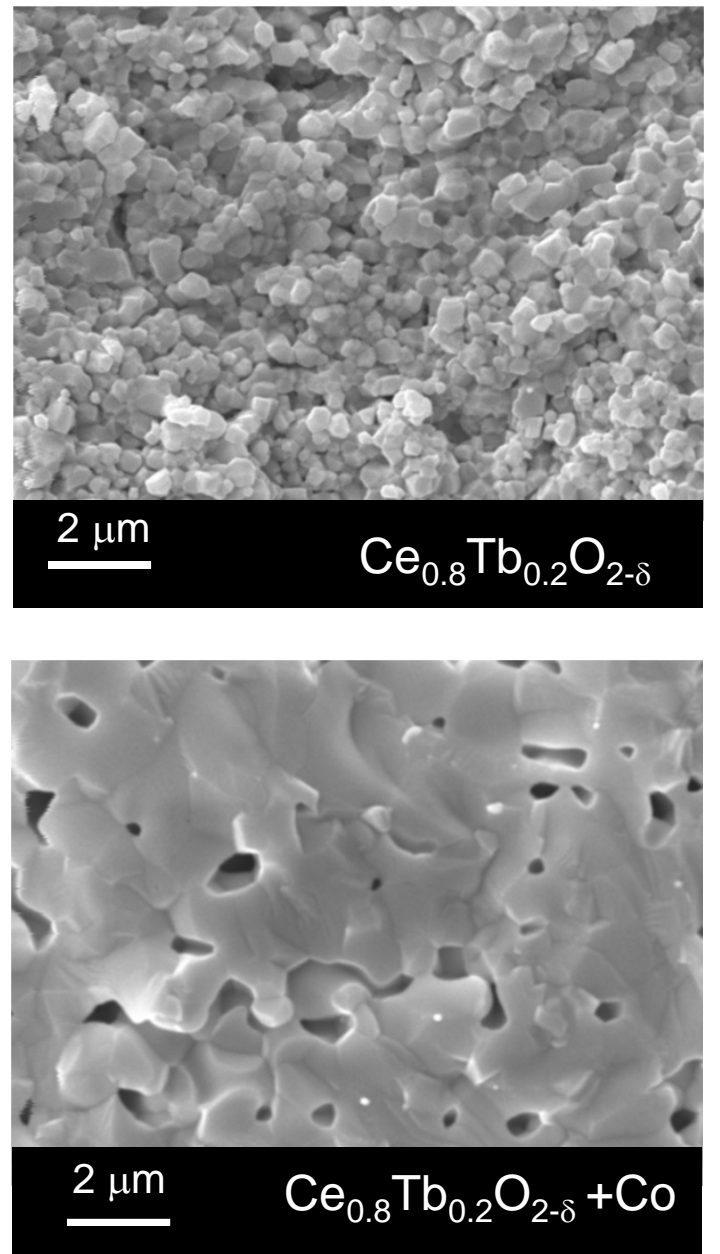
Figure 3

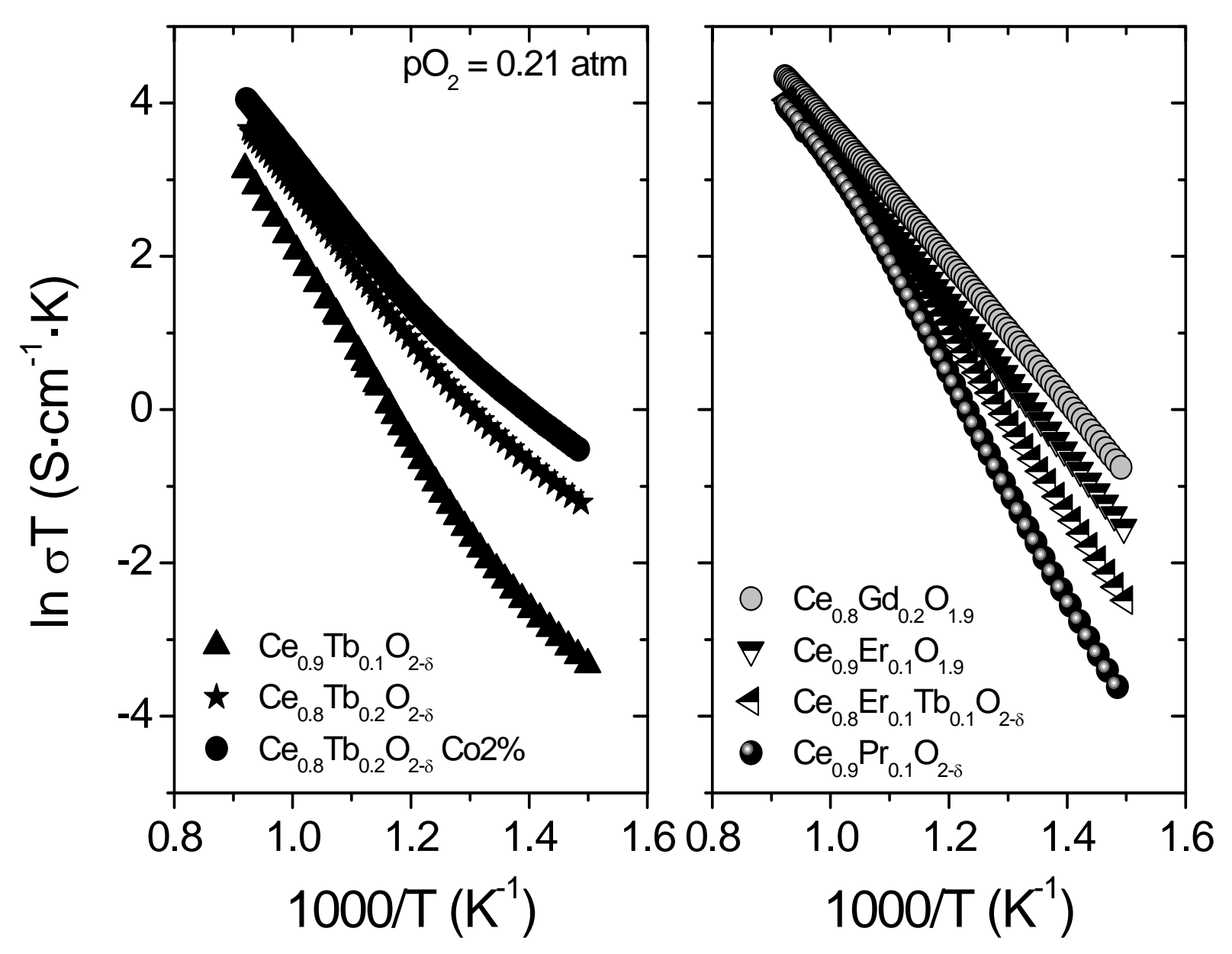


Figure 4

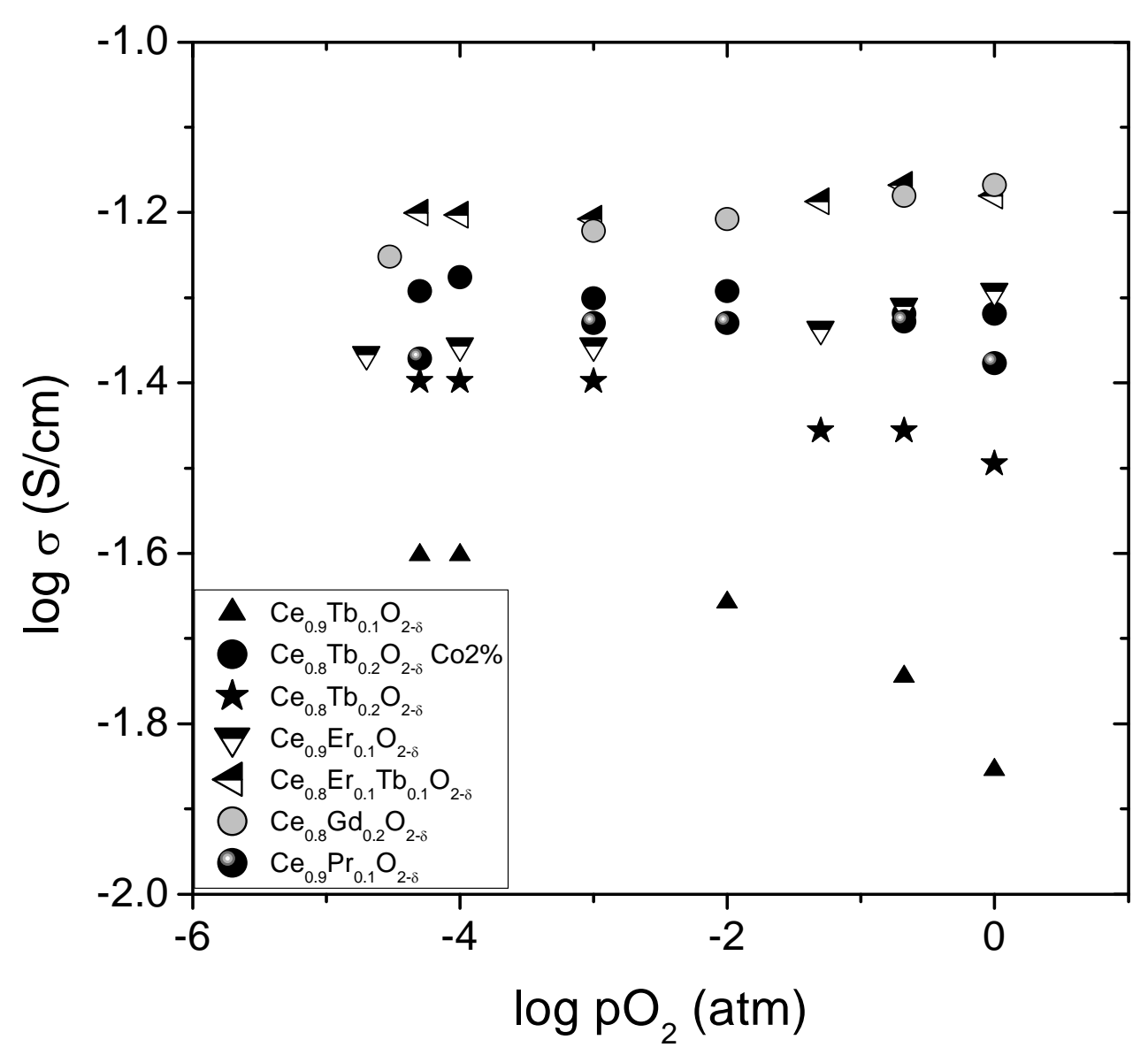


Figure 5

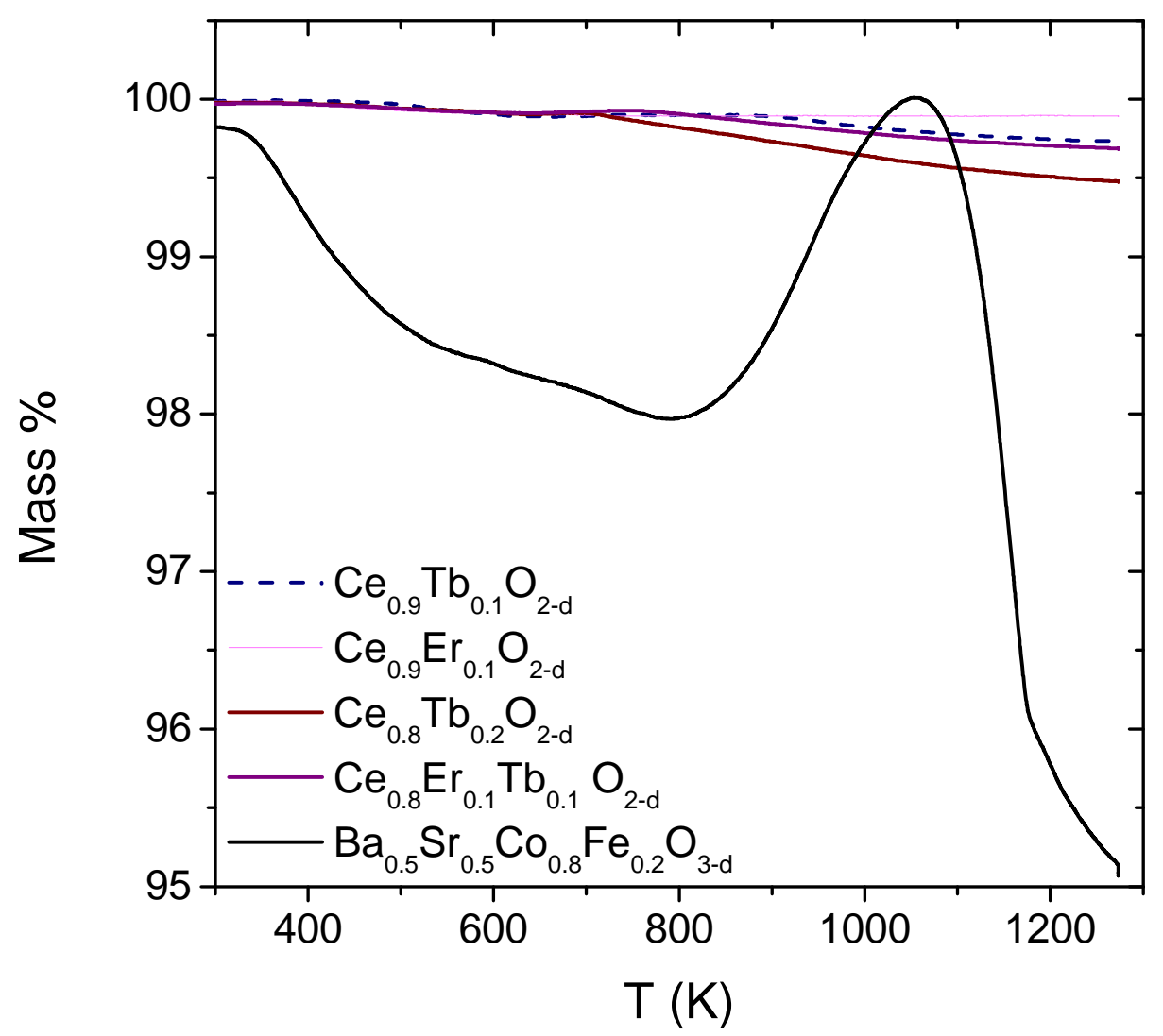


Figure 6
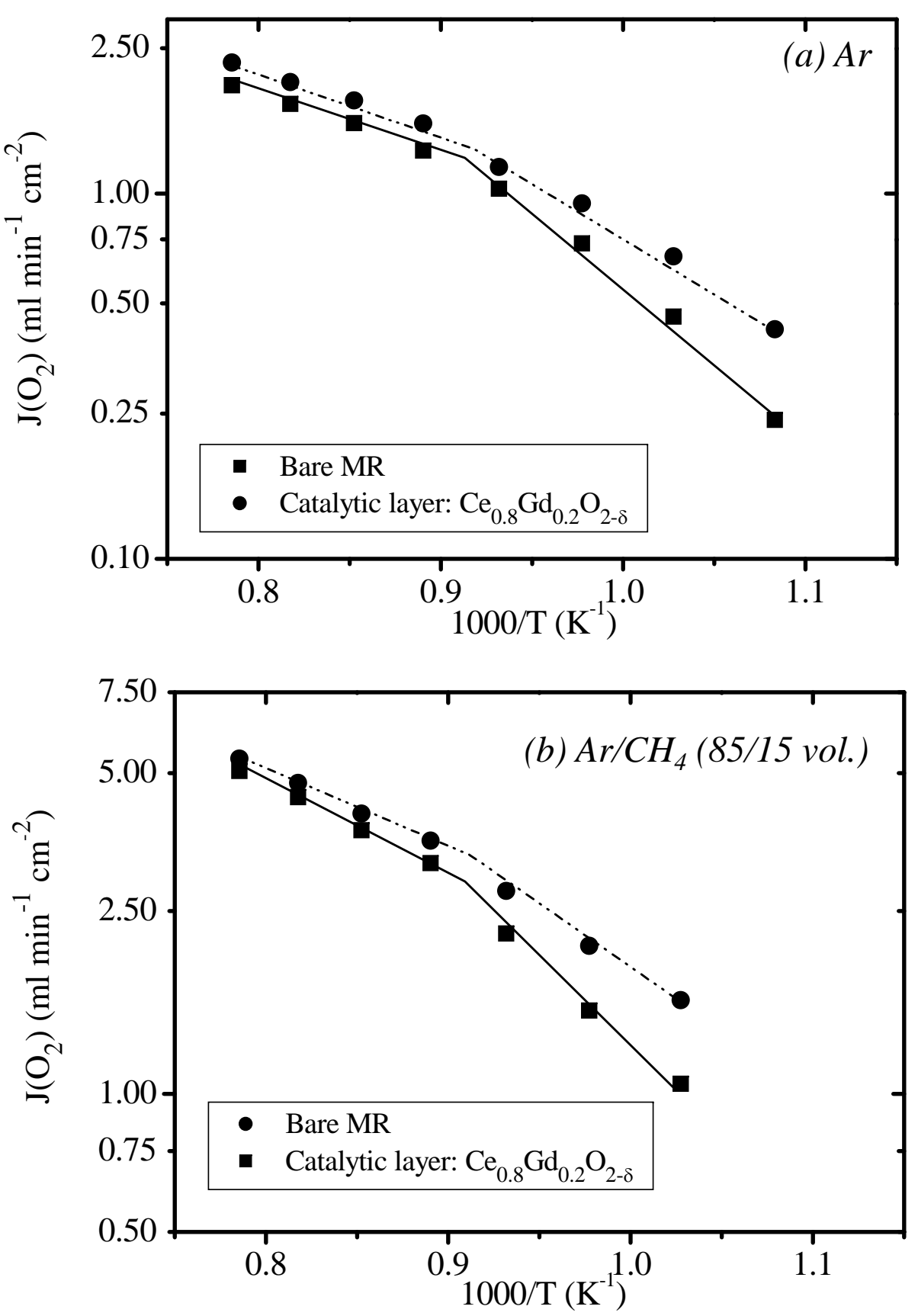
Figure 7

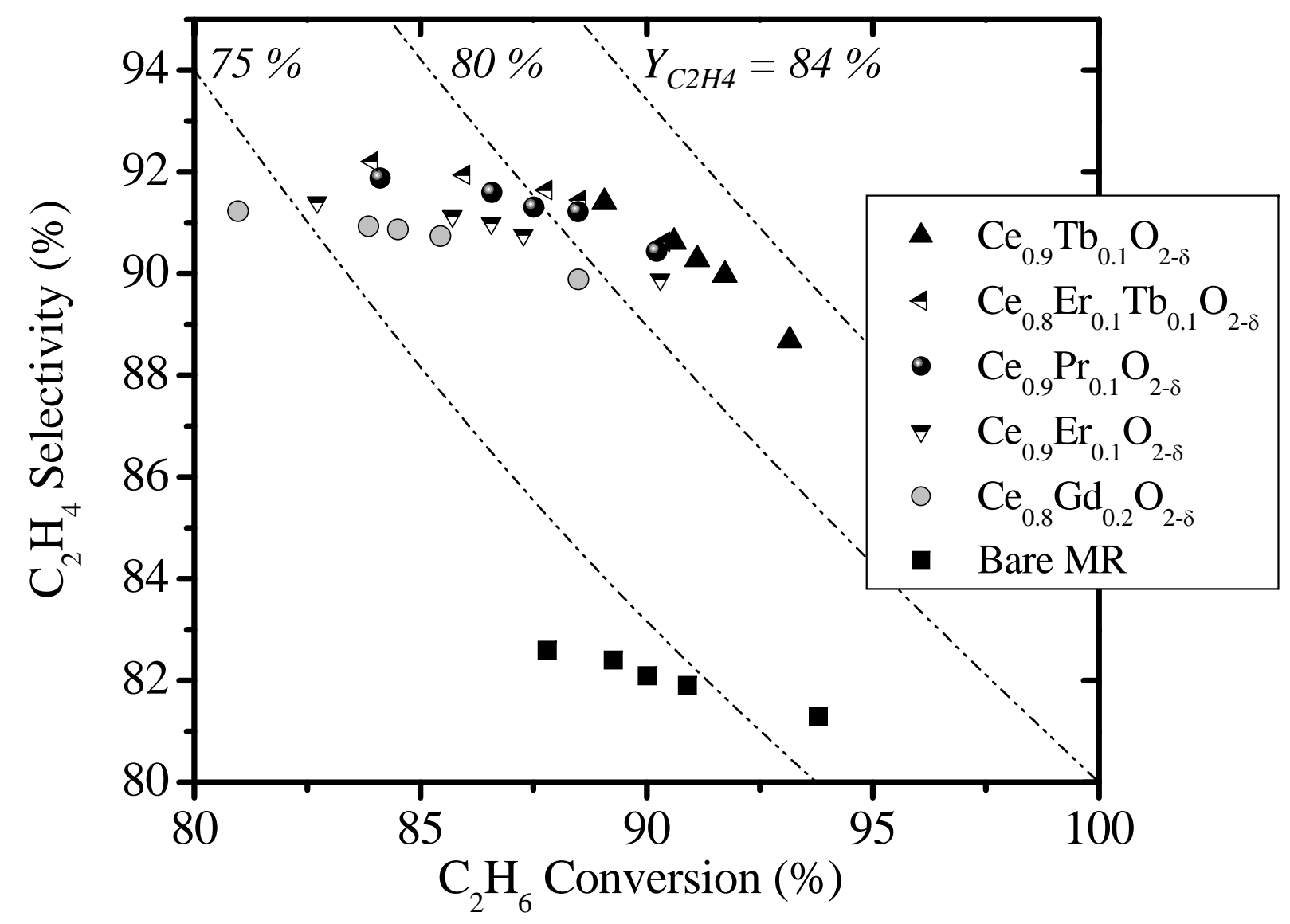


Figure 8
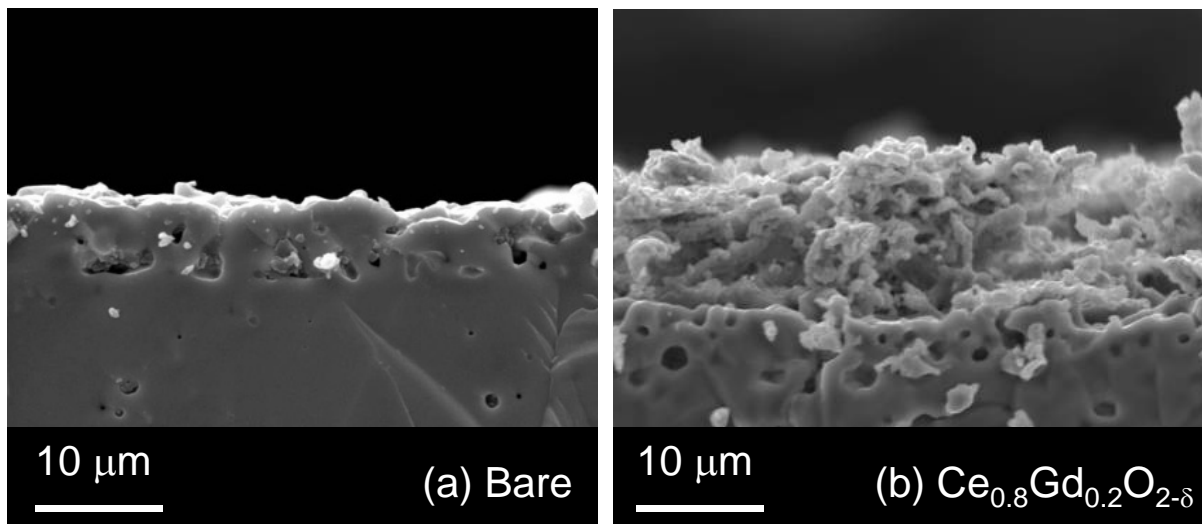

$10 \mu \mathrm{m}$

(a) Bare

(b) $\mathrm{Ce}_{0.8} \mathrm{Gd}_{0.2} \mathrm{O}_{2-\delta}$

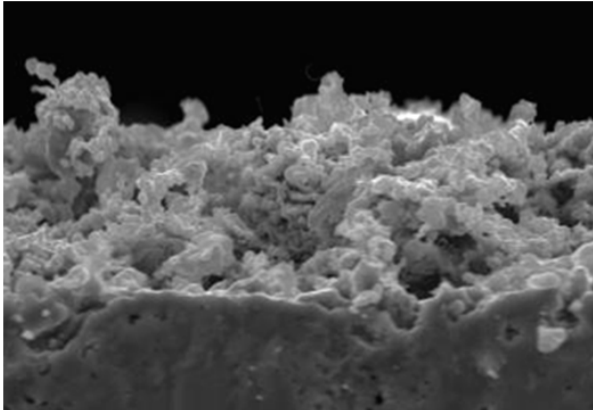

$10 \mu \mathrm{m}$

(c) $\mathrm{Ce}_{0.9} \mathrm{Pr}_{0.1} \mathrm{O}_{2-}$
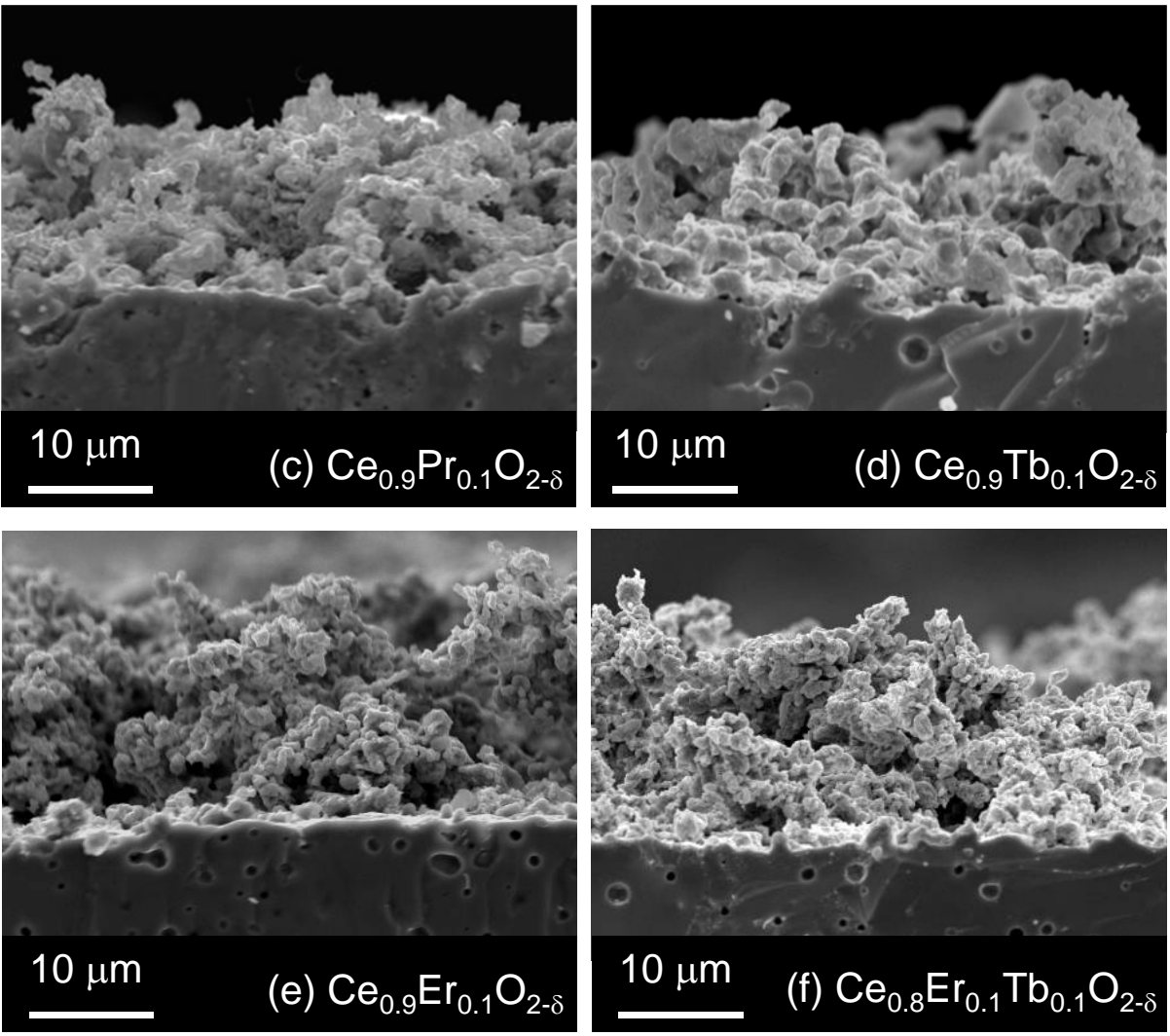
Figure 9
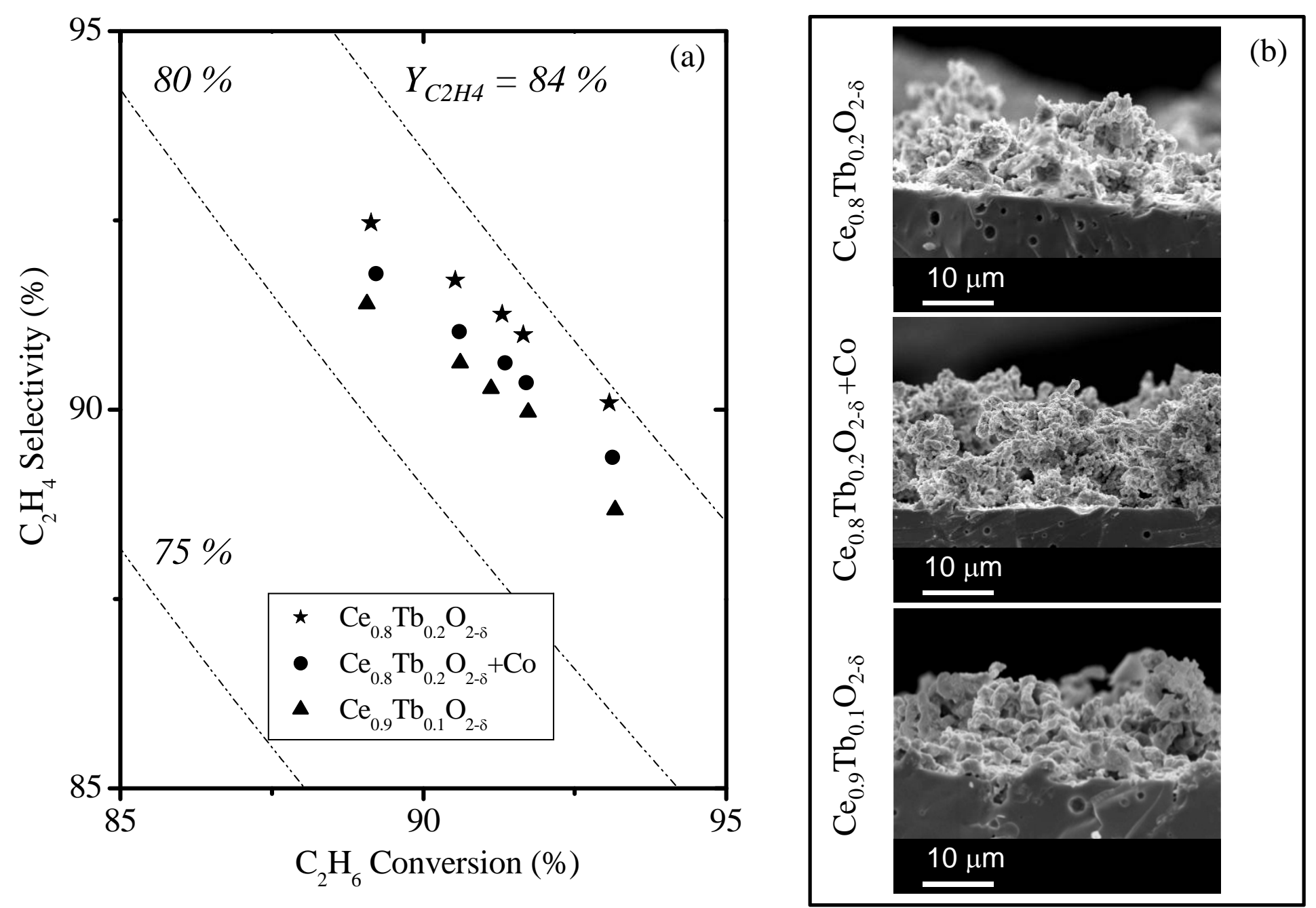


\section{Graphical Abstract}

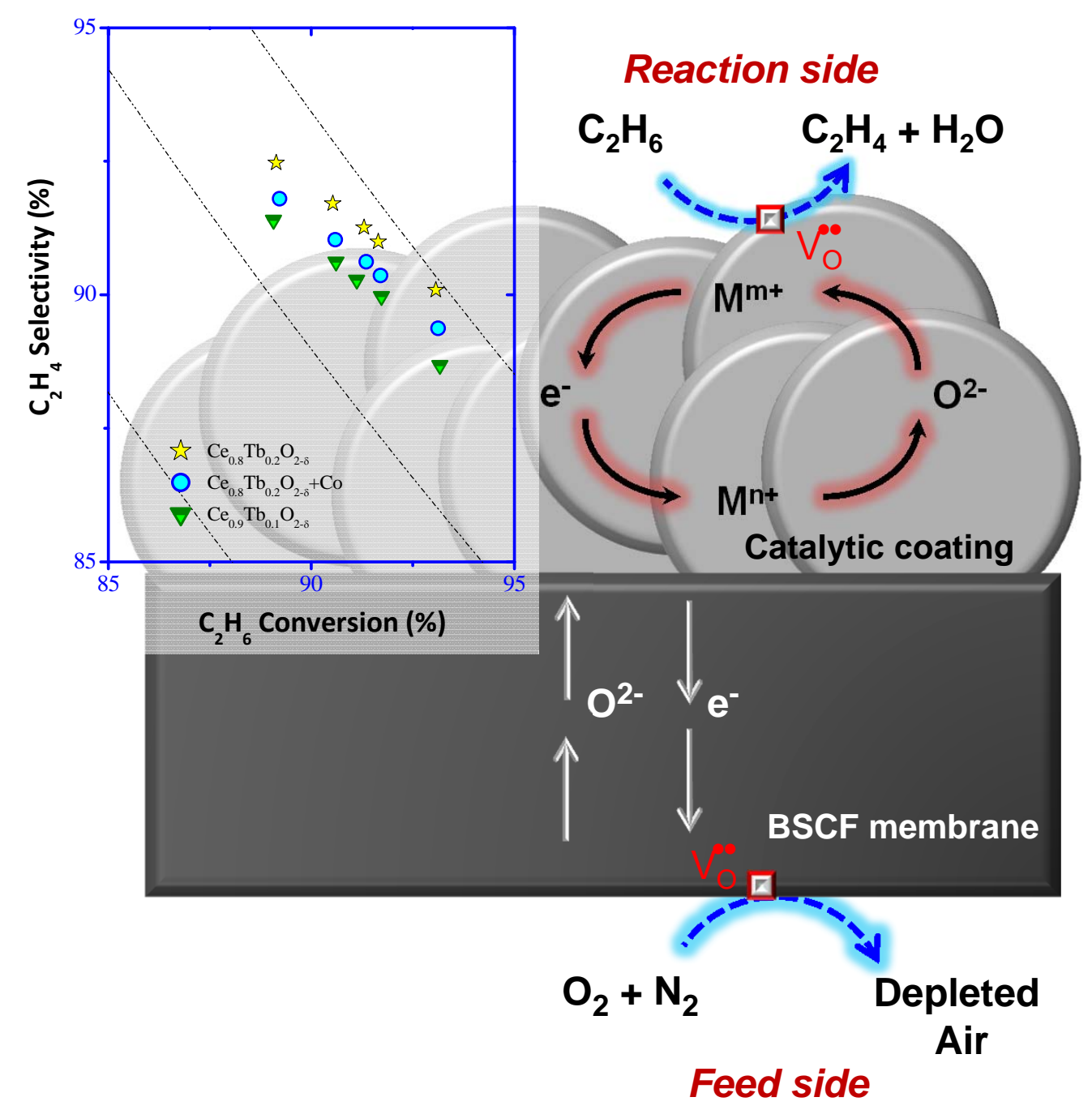




\section{Supporting Information}

Figure S1

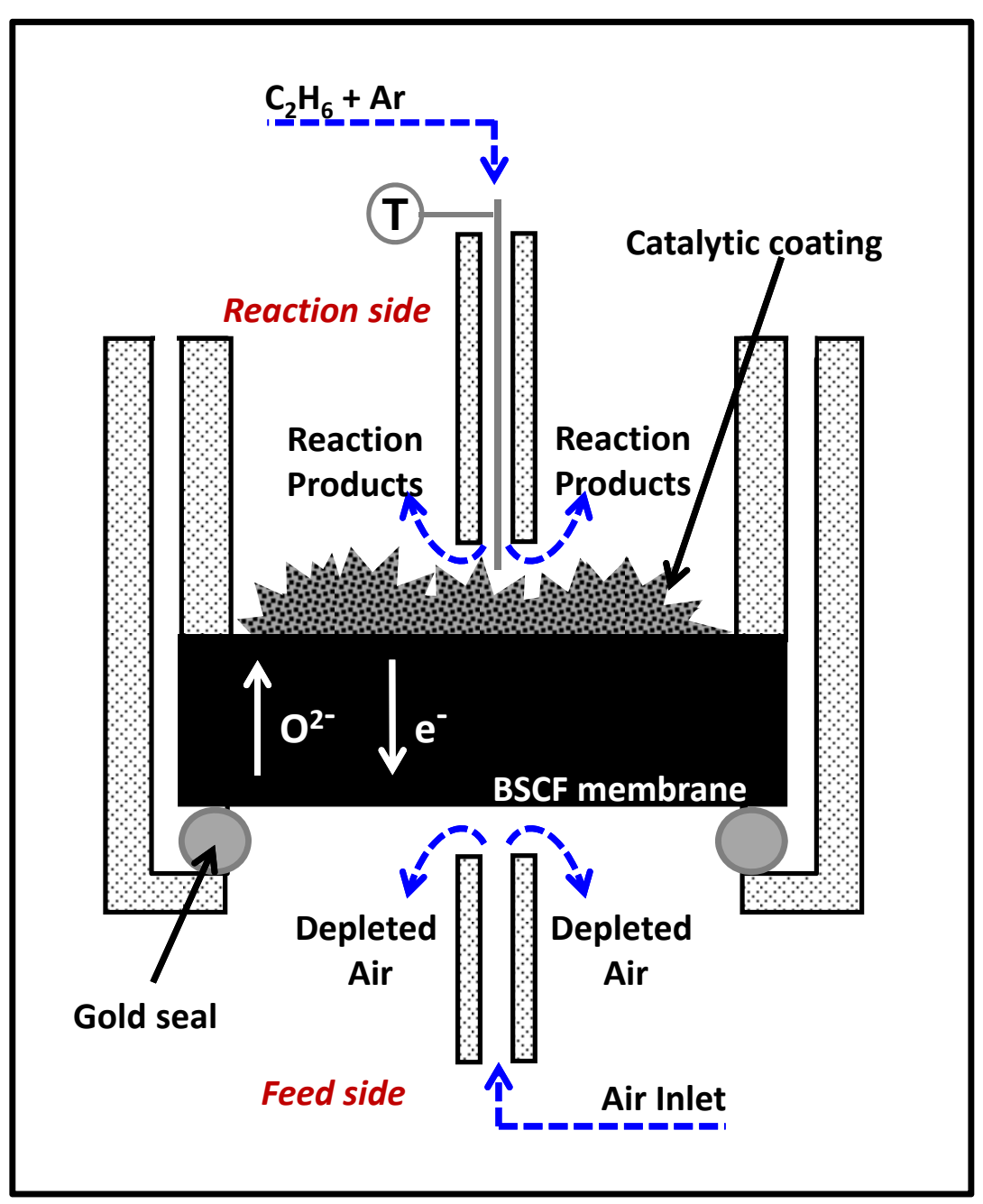

-.Schematic of the quartz membrane reactor design.- 


\section{Supporting Information}
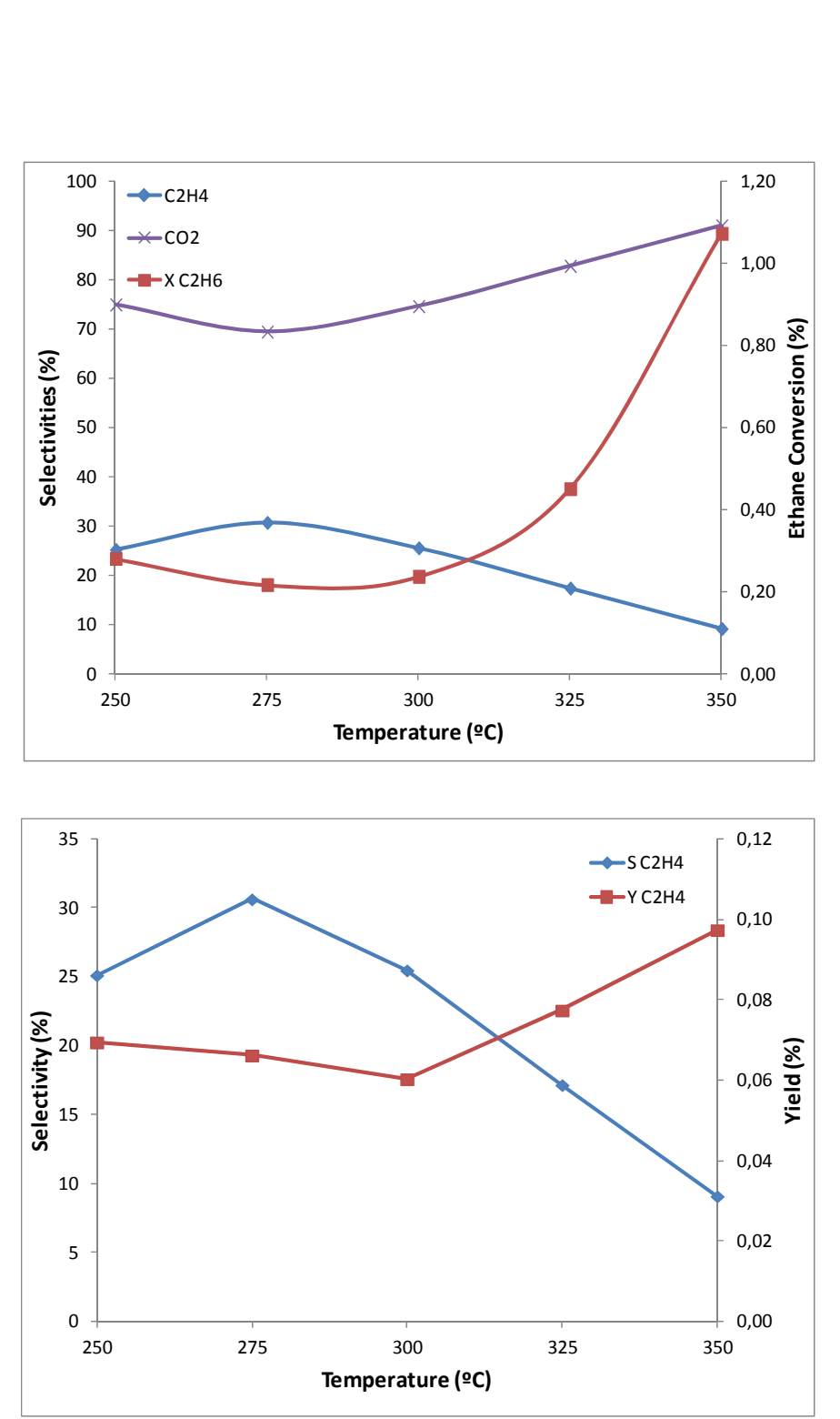

\section{Figure S2}
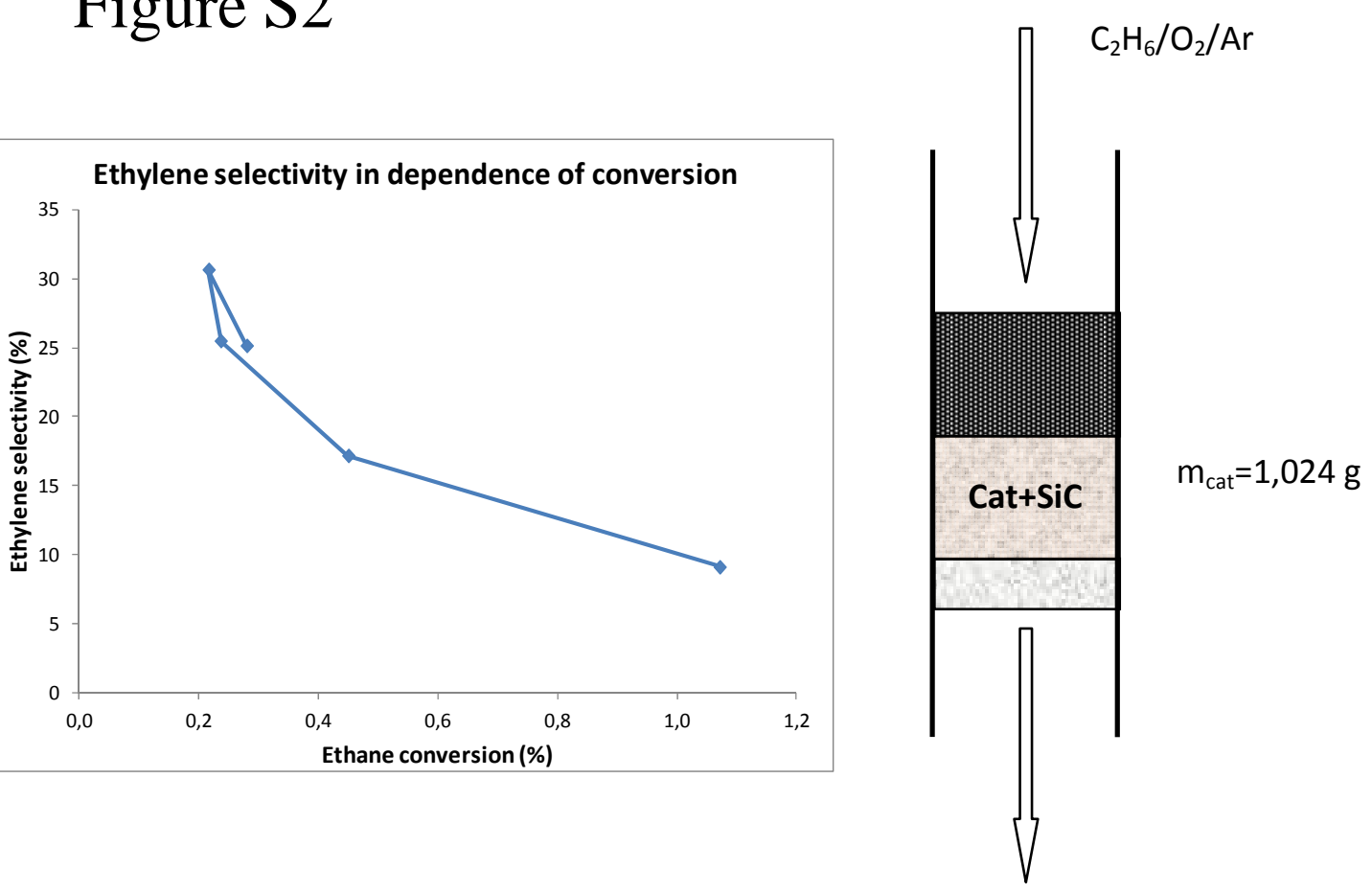

-.Fixed bed reactor test for the best catalyst 20\% Tb doped ceria. $\mathrm{GSHV}=3000 \mathrm{~cm} 3 / \mathrm{gcat} \cdot \mathrm{h}$, Feed 9:3:88 (C2H6/O2/Ar) 


\section{Supporting Information}

\section{Figure S3}
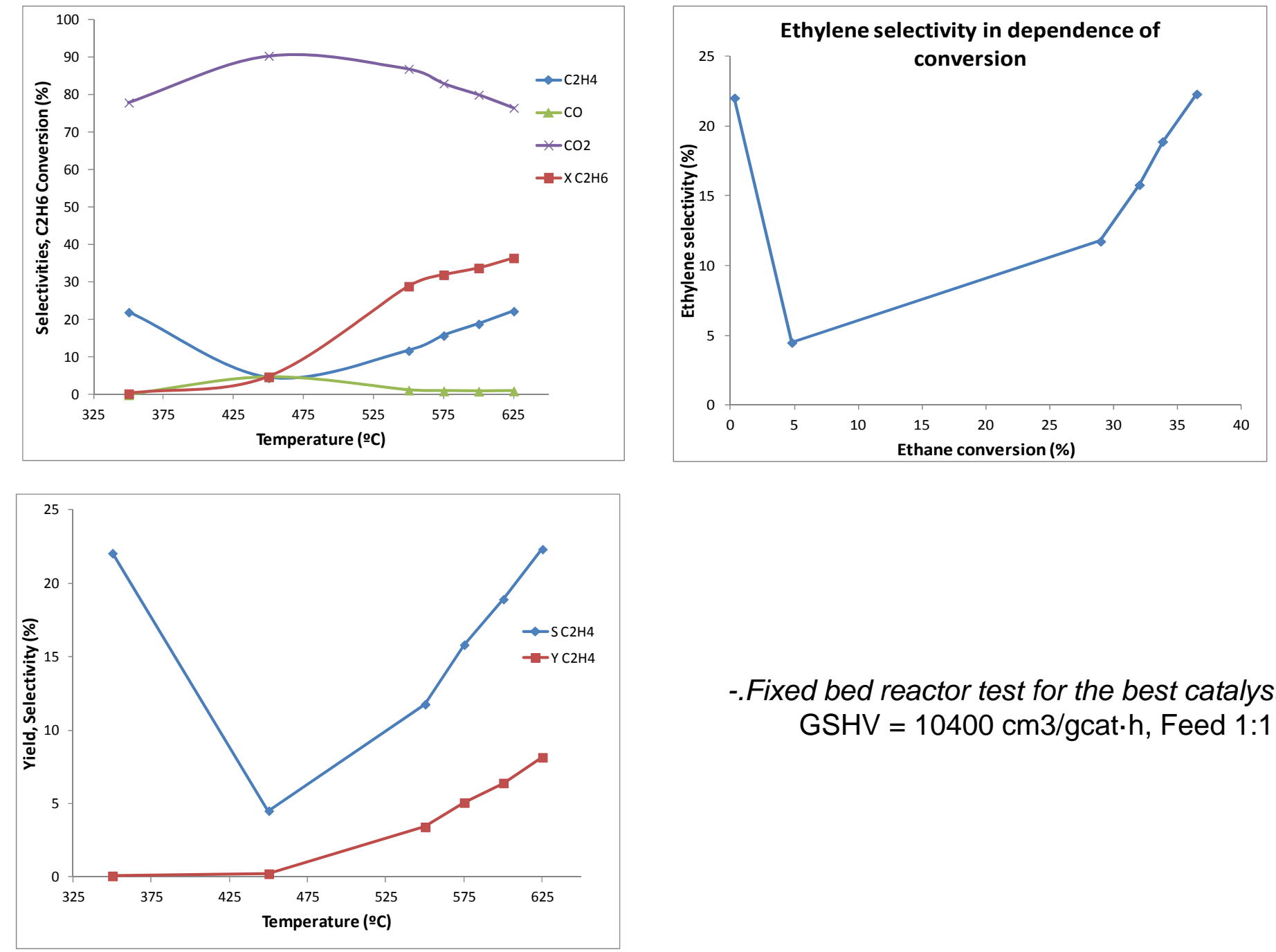

-.Fixed bed reactor test for the best catalyst 20\% Tb doped ceria. $\mathrm{GSHV}=10400 \mathrm{~cm} 3 / \mathrm{gcat} \cdot \mathrm{h}$, Feed 1:1:6 (C2H6/O2/Ar) 